\title{
Determinación y valoración del daño ambiental
}

\author{
Elsa Marina Álvarez González \\ Profesora Ayudante Doctor de Derecho Administrativo \\ Universidad de Málaga \\ Carmen María Ávila Rodríguez \\ Profesora Ayudante Doctor de Derecho Administrativo \\ Universidad de Málaga
}

SUMARIO: I. INTRODUCGIÓN. II. RÉGIMEN JURÍDICO DEL SISTEMA DE RESPONSABILIDAD MEDIOAMBIENTAL. 1. En el ámbito internacional. 2. En el ámbito comunitario. 3. En el ámbito nacional. A. Características generales del sistema de responsabilidad medioambiental. B. El daño ambiental en la Ley de Responsabilidad Medioambiental. a) Características del daño ambiental. b) Agente causante del daño. c) Medidas reparadoras del daño ambiental. C. Carencias del sistema de responsabilidad medioambiental. III. DETERMINACIÓN Y VALORACIÓN DEL DAÑO AMBIENTAL. 1. Los criterios para determinar el daño ambiental establecidos por el legislador ambiental. 2. Métodos de valoración económica del daño ambiental. IV. EL PAPEL DE LA JURISPRUDENCIA INTERNACIONAL EN LA EVOLUCIÓN DEL CONCEPTO DE DAÑO AMBIENTAL Y EN LOS PROCEDIMIENTOS PARA SU DETERMINACIÓN Y VALORACIÓN. 1. El naufragio del Amoco Cádiz. A. El accidente y su contexto. B. El concepto de daño resarcible en el accidente del Amoco Cádiz. C. Hitos a destacar. 2. La explosión, el incendio y el hundimiento del pozo petrolífero Ixtoc-1. A. El accidente y los daños ambientales ocasionados. B. La determinación del daño. C. La mitigación del daño y los pronunciamientos jurisdiccionales. D. Hitos a destacar. 3. El complejo tratamiento de los daños ambientales en los accidentes de los petroleros Patmos y Haven. A. Los accidentes y sus respectivos contextos. B. La posición del Estado Italiano respecto al daño ambiental y los problemas de aplicación del "Sistema de Bruselas". a) El concepto de daño por contaminación en el Sistema de Bruselas. b) Las objeciones del Estado Italiano al concepto de daño por contaminación en el sis- 
tema de Bruselas. Las previsiones del Derecho interno italiano. C. Los pronunciamientos jurisdiccionales que resolvieron la cuestión de la reparación de los daños al Medio Ambiente en los asuntos Patmos y Haven. a) La reparación de los daños en el asunto Patmos. b) La reparación de los daños en el asunto Haven. D. Hitos a destacar. 4. La consideración de los daños al medio Ambiente en el caso de Petrolero Exxon Valdez. A. El accidente y las consecuencias ambientales. B. El procedimiento seguido en el caso para la determinación de los daños ambientales. C. Hitos a destacar. V. CONCLUSIONES. VI. BIBLIOGRAFÍA.

\section{RESUMEN:}

La valoración del daño ambiental es el elemento clave en el sistema de responsabilidad medioambiental, pues sólo a través de ella es posible obtener la reparación efectiva del mismo. En el análisis jurídico que de este concepto se realiza en el presente artículo llama la atención que, ni la legislación internacional, ni el legislador español han previsto unas reglas o normas de valoración del daño ambiental, dando lugar a que esta importantísima cuestión haya quedado al arbitrio de la interpretación judicial, situación ésta, especialmente delicada, ya que en el ámbito de la justicia, el Juez se encuentra con problemas en la mayoría de las ocasiones insuperables a la hora de cuantificar el daño ambiental como se pone de manifiesto en el estudio de la jurisprudencia internacional que se ha realizado.

Palabras clave: Daño ambiental, valoración daño, jurisprudencia internacional.

\section{ABSTRACT:}

The assessment of environmental damage is the key element in the system of environmental responsibility. Only through the valuation of damage is possible to obtain effective redress the same. Legal analysis of this concept made in this article, draws attention that neither international law nor the Spanish legislation has provided a valuation rules or environmental damage, leading to this important question has been the discretion of the judicial interpretation, a situation particularly delicate, since in the field of justice, the judge finds problems in most of the time when second to quantify the environmental damage as evidenced in the study of international jurisprudence that has been done.

Key words: Environmental damage, damage assessment, international jurisprudence 


\section{INTRODUCCIÓN}

El sistema de responsabilidad medioambiental que se implanta en España con la Ley 26/2007, de 27 de octubre, de Responsabilidad Medioambiental, se caracteriza por ser objetivo e ilimitado y basado en los principios de prevención y de que "quien contamina paga". Es objetivo porque sólo atiende a la existencia del daño sin necesidad de que concurra negligencia, dolo o culpa, e ilimitado porque el contenido de la obligación de reparación (o, en su caso, de prevención) que asume el operador responsable consiste en devolver los recursos naturales dañados a su estado original, sufragando el total de los costes a los que asciendan las correspondientes acciones preventivas o reparadoras. $\mathrm{Al}$ poner el énfasis en la restauración total de los recursos naturales y de los servicios que prestan, se prima el valor medioambiental, el cual no se entiende satisfecho con una mera indemnización dineraria.

Elemento indispensable pues de este sistema de responsabilidad medioambiental es la valoración del daño, pues sólo a través de ella es posible obtener la reparación efectiva del mismo. Es obvio que las decisiones administrativas y judiciales a favor de la restauración del daño ambiental, y relativas a la compensación e indemnización necesitan imperativamente de una atribución de valor al "ambiente y sus componentes" cuando éstos resulten afectados. Por tanto, la valoración de los bienes ambientales debe ser la antesala de todo sistema de responsabilidad por daño ambiental, ya que si no se sabe cuánto vale reparar un elemento ambiental, difícilmente se podrá realizar una labor de restauración con mínimas garantías de éxito.

Sin embargo, llama la atención que ni la legislación internacional ni el legislador español hayan prestado atención a este elemento del sistema de responsabilidad medioambiental, pues no existe un régimen jurídico sobre la valoración del daño, quedando sin regulación cuáles deben ser los patrones de reacción y de respuesta frente a un determinado daño ambiental.

La ausencia de unas reglas o normas de valoración del daño ambiental en nuestro ordenamiento jurídico ha dado lugar a que esta importantísima cuestión haya quedado al arbitrio de la interpretación judicial, situación ésta especialmente delicada, ya que en el ámbito de la justicia, el Juez se encuentra con problemas en la mayoría de las ocasiones insuperables a la hora de cuantificar el daño ambiental: falta de normativa que lo oriente, indeterminación de la metodología a utilizar o falta de criterios valorativos propios. Estos problemas se ponen de manifiesto cada vez que tiene lugar una catástrofe ambiental y se deben depurar las respectivas responsabilidades, como por ejemplo, y por citar 
sólo algunos de los más recientes, el desastre del Prestige en $2002^{1}$, cuyo procedimiento judicial dura ya más de nueve años, o el desastre ecológico del Golfo de México en 2010 causado por el derrame de petróleo producido con la explosión de una plataforma petrolífera de la empresa British Petroleum.

Es precisamente esta cuestión la que nos lleva a examinar la determinación y valoración del daño ambiental en nuestro sistema jurídico, analizando el régimen jurídico de responsabilidad medioambiental desde la perspectiva del daño y los diferentes métodos de valoración existentes. Pero además, hemos considerado necesario entrar a analizar distintos accidentes industriales que tuvieron como consecuencia graves daños ambientales: el naufragio del buque petrolero Amoco Cádiz, la explosión, incendio y hundimiento del pozo petrolífero Ixtoc-1, los naufragios de los petroleros Patmos y Haven y el accidente del superpetrolero Exxon Valdez. Los cuatro asuntos que se van a tratar tienen en común que produjeron grandes vertidos de hidrocarburos al mar. Ahora bien, lejos de entrar a analizar las complejas cuestiones de Derecho Internacional, el reconocimiento y la determinación de la responsabilidad de los autores de los daños y los enmarañados procesos judiciales que se originaron en cada uno de estos asuntos, nos hemos centrado en el tratamiento que en cada uno de ellos se dio a los daños ambientales y cuáles fueron los métodos y procedimientos de evaluación y determinación de los mismos, con la finalidad de poner de relieve cómo ha ido evolucionando el concepto de daño ambiental y resaltar el papel que la jurisprudencia internacional ha tenido en la concreción de los procedimientos de valoración y determinación de los daños ambientales.

Con este análisis, queremos poner de manifiesto que el poder judicial junto con el poder legislativo desempeñan una función decisiva en la protección del medio ambiente, siendo fundamental dotar a los jueces y tribunales de unos mecanismos objetivos y consensuados de valoración del daño ambiental y dejar las "reglas de la sana crítica" usadas actualmente por el órgano judicial para valorar determinados bienes ambientales, como elemento complementario y no principal de esa valoración, en aras de robustecer el principio de seguridad jurídica que debe respetarse en todo procedimiento judicial.

\footnotetext{
${ }^{1}$ Por citar otros desastres naturales en el dominio público marítimo terrestre: Erika frente a Bretaña (1999), Sea Empress en Gales (1996), Aegean Sea en la bocana del puerto de A Coruña (1992), Exxon-Valdez en Alaska (1989), Kharg-5 al Norte de Canarias (1989) y Amoco Cádiz de nuevo en Bretaña (1978).
} 


\section{RÉGIMEN JURÍDICO DEL SISTEMA DE RESPONSABILI- DAD MEDIOAMBIENTAL}

La dimensión global que ha adquirido la protección del medio ambiente como elemento fundamental de la sostenibilidad económica y social ${ }^{2}$ hace que el marco normativo de referencia del sistema de responsabilidad medioambiental esté constituido por un conjunto de normas a nivel internacional, comunitario y nacional.

\section{En el ámbito internacional}

A nivel internacional son relevantes la Declaración de Naciones Unidas sobre el medio humano, firmada en Estocolmo en 1972, y la Declaración de Naciones Unidas sobre el medio ambiente y el desarrollo, firmada en Río de Janeiro en 1992, pues aunque no atienden a la responsabilidad medioambiental si que introducen los principios fundamentales para la protección del medio ambiente. Entre ellos, podemos destacar, en lo que a nosotros nos interesa, el principio 2 de la Declaración de Río de Janeiro que establece que "De conformidad con la Carta de las Naciones Unidas y los principios del derecho internacional, los Estados tienen el derecho soberano de aprovechar sus propios recursos según sus propias politicas ambientales y de desarrollo, y la responsabilidad de velar porque las actividades realizadas dentro de su jurisdicción o bajo su control no causen daños al medio ambiente de otros Estados o de zonas que estén fuera de los limites de la jurisdicción nacional", y el principio 13 de la misma Declaración que dispone que "Los Estados deberán desarrollar la legislación nacional relativa a la responsabilidad y la indemnización respecto de las víctimas de la contaminación y otros daños ambientales. Los Estados deberán cooperar asimismo de manera expedita y más decidida en la elaboración de nuevas leyes internacionales sobre responsabilidad e indemnización por los efectos adversos de los daños ambientales causados por las actividades realizadas dentro de su jurisdicción o, bajo su control, en zonas situadas fuera de su jurisdicción".

\section{En el ámbito comunitario}

A nivel comunitario, debemos señalar en primer lugar, el Tratado de Lisboa de 2007 que ha venido a modificar el Tratado Constitutivo de la Unión Euro-

\footnotetext{
${ }^{2}$ La relación entre el medio ambiente y la economía se definió de forma explícita en 1992 en el Quinto Programa de Acción Comunitario en materia de Medio Ambiente, cuando se consideró que el crecimiento económico es insostenible "si no se tienen en cuenta las consideraciones medio ambientales, no sólo como un factor restrictivo, sino como un incentivo para aumentar la eficacia y la competitividad, sobre todo en el mercado mundial" (Comisión de Comunidades Europeas, 1992).
} 
pea, y en lo que a nosotros nos interesa, si bien mantiene la regulación anterior de la política medioambiental de la Unión Europea, en el nuevo Tratado se incluye de forma expresa entre los objetivos de la Unión la lucha contra el cambio climático. En él se establecen los principios básicos sobre los que se asienta todo el sistema de la responsabilidad medioambiental. Así el artículo 191.2 establece: "La política de la Comunidad en el ámbito del medio ambiente tendrá como objetivo alcanzar un nivel de protección elevado, teniendo presente la diversidad del situaciones existentes en las distintas regiones de la Comunidad. Se basará en los principios de cautela y de acción preventiva, en el principio corrección de los atentados al medio ambiente, preferentemente en la fuente misma, y en el principio de quien contamina paga".

Además, y específicamente sobre responsabilidad medioambiental, es preciso destacar la Directiva 2004/35/CE del Parlamento Europeo y del Consejo, de 21 de abril, sobre responsabilidad medioambiental en relación con la prevención y reparación de daños medioambientales. En ella se regulan las bases del sistema de responsabilidad medioambiental que deben respetarse por los Estados miembros. En este sentido, la Directiva establece un marco de responsabilidad medioambiental, basado en el principio de "quien contamina paga", para la prevención y la reparación de los daños medioambientales. En este contexto, por daño debe entenderse el cambio adverso mensurable de un recurso natural o el perjuicio mensurable a un servicio de recursos naturales, tanto si se producen directa como indirectamente, siendo daño ambiental los daños a las especies y hábitats naturales protegidos (cualquier daño que produzca efectos adversos significativos en la posibilidad de alcanzar o de mantener el estado favorable de conversación de dichos hábitats o especies), los daños a las aguas (cualquier daño que produzca efectos adversos significativos en el estado ecológico, químico o cuantitativo, o en el potencial ecológico de las aguas) y los daños al suelo (cualquier contaminación del suelo que suponga un riesgo significativo de que se produzcan efectos adversos para la salud humana debidos a la introducción directa o indirecta de sustancias, preparados, organismos o microorganismos en el suelo o subsuelo).

El principio fundamental sobre el que se asienta el sistema de responsabilidad medioambiental consiste en que un operador cuya actividad haya causado daños al medio ambiente o haya supuesto una amenaza inminente de tales daños sea declarado responsable desde el punto de vista financiero a fin de inducir a los operadores a adoptar medidas y desarrollar prácticas dirigidas a minimizar los riesgos de que se produzcan daños medioambientales, de forma que se reduzca su exposición a responsabilidades financieras. Por tanto, el operador que cause daños medioambientales o que amenace de forma inminente con causar tales daños debe sufragar, en principio, el coste de las medidas pre- 
ventivas o reparadoras necesarias. De ahí que cuando una autoridad competente actúe por sí misma o a través de un tercero en lugar de un operador, dicha autoridad debe garantizar que el coste en que haya incurrido se cobre al operador.

Para garantizar el sistema de responsabilidad medioambiental, la Directiva regula dos tipos de acciones frente a los daños ambientales o amenazas de que se produzcan: una acción preventiva cuando aún no se haya producido el daño pero exista riesgo o amenaza de que se produzca, en la que el operador deberá adoptar las medidas preventivas oportunas, debiendo poner en conocimiento de la autoridad competente la realidad de la situación cuando a pesar de la adopción de dichas medidas, la situación de peligro no haya desaparecido; y una acción reparadora si ya se ha producido el daño, en la que el operador estará obligado a comunicarlo a la autoridad competente y adoptar en la mayor brevedad posible las medidas reparadoras necesarias.

Como protección del propio sistema de responsabilidad medioambiental, la Directiva recoge la posibilidad de ejercer una acción de solicitud por toda persona física o jurídica que se vea afectada por un daño medioambiental o tenga un interés suficiente en la toma de decisiones de carácter medioambiental referentes al daño, o alegue la vulneración de un derecho. El ejercido de dicha acción de solicitud permite acudir a la autoridad competente y solicitar el cumplimiento de esta Directiva, pudiendo con posterioridad interponer recurso ante un tribunal o cualquier otro órgano público independiente e imparcial respecto de las decisiones, actos u omisiones de la autoridad competente ${ }^{3}$.

\section{En el ámbito nacional}

A nivel nacional, por su parte, debemos indicar la Ley 26/2007, de 27 de octubre, de Responsabilidad Medioambiental y el Real Decreto 2090/2008, de 22 de diciembre, por el que se aprueba el Reglamento de desarrollo parcial de la Ley de Responsabilidad Medioambiental, que vienen a consolidar en nues-

\footnotetext{
${ }^{3}$ Según el art. 12.1 de la Directiva, corresponderá a los Estados miembros determinar lo que constituye «interés suficiente» y «vulneración de un derecho». Con este fin, se considerará interés suficiente en la toma de decisiones de carácter medioambiental relativas al daño, el interés de las organizaciones no gubernamentales que trabajen en la protección del medio ambiente y que cumplan los requisitos establecidos por la legislación nacional. Se considerará asimismo que dichas organizaciones tienen derechos que pueden ser vulnerados a efectos de interponer la acción de solicitud.
} 
tro ordenamiento jurídico un sistema de responsabilidad medioambiental de naturaleza administrativa a cuyo análisis dedicamos el siguiente apartado.

A. Características generales del sistema de responsabilidad medioambiental

La Ley 26/2007, de 27 de octubre, de Responsabilidad Medioambiental, en adelante LRM, traspone a nuestro ordenamiento jurídico la Directiva 2004/35/CE del Parlamento Europeo y del Consejo, de 21 de abril, sobre responsabilidad medioambiental en relación con la prevención y reparación de daños medioambientales, implantando un régimen administrativo de responsabilidad ambiental de carácter objetivo e ilimitado basado en los principios de prevención y de que quien contamina paga. En ella se instituye todo un conjunto de potestades administrativas con cuyo ejercicio la Administración pública debe garantizar el cumplimiento de la ley y la aplicación del régimen de responsabilidad que incorpora.

La LRM se aplica a los daños medioambientales y a las amenazas inminentes de que tales daños ocurran. Ahora bien, no cualquier daño a elementos del medio ambiente constituye un daño medioambiental a efectos de la Ley. Existirá daño medioambiental cuando se cause un cambio adverso y mensurable en alguno de los siguientes elementos, en la relación entre ellos, o en la relación entre alguno de estos elementos y el público: a) especies silvestres y hábitats; b) aguas; c) ribera del mar y de las rías; y d) suelo ${ }^{4}$.

En este régimen de responsabilidad medioambiental pueden ser responsables las personas físicas o jurídicas, públicas o privadas, que desempeñen una actividad profesional o empresarial o que, en virtud de cualquier título, controlen dicha actividad o tengan un poder económico determinante sobre su funcionamiento técnico. Estas personas son denominadas "operadores".

\footnotetext{
${ }^{4}$ Queda excluido del ámbito de aplicación de la LRM según lo dispuesto en el art.3.4 y 5: a) los daños medioambientales y las amenazas inminentes cuando tengan su origen en un suceso cuyas consecuencias estén previstas en determinados convenios internacionales; b) los riesgos nucleares; c) los daños medioambientales y las amenazas inminentes derivados de un conflicto armado, hostilidades, guerra civil o insurrección y los causados por fenómenos naturales de carácter excepcional, inevitable e irresistible; d) los daños medioambientales y las amenazas inminentes de que tales daños se produzcan causados por una contaminación de carácter difuso; y e) los daños causados a las personas, a sus derechos o a sus bienes (salvo que estos últimos constituyan un recurso natural) aunque sean consecuencia de los mismos hechos que dan origen a responsabilidad medioambiental.
} 
Como regla general, los operadores de cualquier actividad profesional o económica susceptible de producir un daño medioambiental, recogidas en el Anexo III de la Ley, son los obligados a adoptar y ejecutar las medidas preventivas, de evitación y de reparación de los daños medioambientales, así como a sufragar sus costes, cualquiera que sea su cuantía, cuando resulten responsables de los mismos. No obstante, la LRM establece una presunción en virtud de la cual, salvo prueba en contrario, se considera que las actividades económicas o profesionales del Anexo III han causado el daño o la amenaza de que el daño se produzca, cuando atendiendo a su naturaleza intrínseca o a la forma en la que han sido desarrolladas sean apropiadas para haber causado dicho daño o amenaza (art. 3.1 LRM).

En todo caso, los operadores deben informar inmediatamente a la autoridad competente de todos los aspectos relativos a los daños medioambientales o a la amenaza de tales daños así como cumplir las decisiones dictadas por dicha autoridad cuando ésta considere que existe amenaza de producción de nuevos daños.

La LRM contempla la posibilidad de que sea la Administración competente la que ejecute por sí misma las medidas de prevención, evitación y reparación. Esta actuación directa de la Administración está prevista cuando no se haya podido identificar al operador responsable y no quepa esperar a ello sin peligro de que se produzcan daños medioambientales; que haya diversos operadores responsables y no sea posible una distribución eficaz en el tiempo y en el espacio que garantice la correcta ejecución de las medidas; que se requieran estudios, conocimientos o medios técnicos que así lo aconsejen; que sean necesarias actuaciones en bienes de las Administraciones públicas o en los de propiedad privada de terceros que hagan difícil o inconveniente su realización por el operador responsable; que la gravedad y la trascendencia del daño así lo exijan. En todos estos supuestos, la Administración pública podrá, cuando proceda, repercutir el importe de los costes correspondientes al operador responsable ${ }^{5}$.

Precisamente para garantizar la responsabilidad económica de los operadores en los costes de la prevención, evitación y reparación de los daños ambientales, la LRM establece la obligación de los operadores de las actividades incluidas en su Anexo III de constituir una garantía financiera que cubra la responsabilidad medioambiental inherente a la actividad o actividades que el operador desarrolle. Esta garantía podrá consistir en una póliza de seguro, un aval

\footnotetext{
${ }^{5}$ Art. 23 LRM.
} 
bancario o una reserva técnica mediante la dotación de un fondo ad hoc. La cantidad que, como mínimo, deberá quedar garantizada será determinada por la autoridad competente, según los criterios que se establezcan reglamentariamente. En ningún caso, esa cantidad será superior a veinte millones de euros.

Es preciso destacar que la exigibilidad de la garantía financiera obligatoria para los operadores sujetos a responsabilidad objetiva dependerá de la aprobación de las órdenes ministeriales a las que se refiere la disposición final cuarta de la $\mathrm{LRM}^{6}$. En este sentido, existe próximo a su aprobación un proyecto de Orden Ministerial del Ministerio de Medio Ambiente, Medio Rural y Marino, publicado el 21 de julio de 2010 para su información pública, en el que se ha realizado una priorización de las actividades recogidas en el Anexo III de la LRM en función de la repercusión o la peligrosidad del sector o grupo de actividades profesionales y que oscila entre $\mathrm{F}$ (máxima prioridad) y A (nivel de prioridad más bajo). A partir de esta priorización se establece el siguiente calendario: las órdenes ministeriales de exigibilidad de la garantía financiera obligatoria a los sectores de actividad que estén clasificados con la letra F se publicarán a partir de los dos años desde la entrada en vigor de esta orden, las relativas a los sectores clasificados con la letra E se publicarán a partir de los tres años, y a partir de los cinco años desde la entrada en vigor de esta orden para los sectores de actividad que estén clasificados con las letras A, B, C y D $\mathrm{D}^{7}$.

\section{B. El daño ambiental en la Ley de Responsabilidad Medioambiental}

El daño ambiental, sin duda, constituye el elemento necesario para poder accionar el sistema de responsabilidad medioambiental. De ahí que la LRM delimite el concepto de daño ambiental, establezca el régimen jurídico del potencial agente causante del daño y regule las medidas de reparación en caso de producirse un daño.

\footnotetext{
${ }^{6}$ Que establece que la fecha a partir de la cual será exigible la constitución de la garantía financiera obligatoria para cada una de las actividades del anexo III se determinará por orden del Ministro de Medio Ambiente, previo acuerdo de la Comisión Delegada del Gobierno para Asuntos Económicos, y previa consulta a las comunidades autónomas y a los sectores afectados. La orden establecerá un calendario específico para las actividades que hubieran sido autorizadas con anterioridad a su publicación. Estas órdenes ministeriales se aprobarán a partir del 30 de abril de 2010 y en su elaboración se tomará en consideración el informe de la Comisión Europea al que se refiere el artículo 14.2 de la Directiva 2004/35/CE del Parlamento Europeo y del Consejo, de 21 de abril de 2004, así como la capacidad de los mercados financieros para disponer de una oferta de garantías completa y generalizada a precios razonables.

${ }^{7}$ El orden de prioridad de los sectores profesionales incluidos en el anexo III de la LRM puede consultarse en: http://www.marm.es/es/calidad-y-evaluacion-ambiental/temas/responsabilidad-mediambiental/OM_RMA_Priorizacion_correccion_errores_tcm7-3849.pdf
} 
En cuanto a la delimitación del concepto de daño ambiental, el propio legislador, consciente de la dificultad de determinar cuando nos encontramos ante un daño ambiental, incorpora, siguiendo la tradición de Derecho comunitario, en su artículo 2 toda una serie de definiciones necesarias para la mejor comprensión de su regulación. Entre ellas, son relevantes por lo que al daño ambiental se refiere las siguientes:

- Daño: cambio adverso y mensurable de un recurso natural o el perjuicio de un servicio de recursos naturales, tanto si se produce directa como indirectamente. Quedan incluidos en el concepto de daño aquellos daños medioambientales que hayan sido ocasionados por los elementos transportados por el aire.

- Daño ambiental: cuando se cause un cambio adverso y mensurable en alguno de los siguientes elementos, en la relación entre ellos, o en la relación entre alguno de estos elementos y el público: (a) especies silvestres y hábitats; (b) aguas; (c) ribera del mar y de las rías; y (d) suelo.

- Amenaza inminente de daños: probabilidad suficiente de que se produzcan daños medioambientales en un futuro próximo.

- Estado básico: estado en que se hallarían los recursos naturales y los servicios que prestan en caso de no haberse producido el daño medioambiental.

Por tanto, el sistema de responsabilidad medioambiental entrará en funcionamiento siempre que se produzca o exista una probabilidad suficiente de que se produzca un cambio adverso y mensurable en las especies silvestres y hábitats, el agua, la ribera del mar y de las rías y el suelo. En definitiva, el legislador opta por un concepto de daño ambiental de contenido ecológico quedando fuera del mismo todo daño patrimonial que según la LRM será accionable por los particulares en vía civil o contencioso-administrativa ${ }^{8}$. No obstante, pudiendo resultar acertada la exclusión de las acciones para reclamar los daños patrimoniales, entendemos que la definición de daño ambiental debería contemplar los daños medioambientales que se produzcan sobre elementos (aguas,

\footnotetext{
${ }^{8}$ En efecto, el art. 5 LRM establece que la Ley no ampara el ejercicio de acciones por lesiones causadas a las personas, a los daños causados a la propiedad privada, a ningún tipo de pérdida económica ni afecta a ningún derecho relativo a este tipo de daños o cualesquiera otros daños patrimoniales que no tengan la condición de daños medioambientales, aunque sean consecuencia de los mismos hechos que dan origen a responsabilidad medioambiental. Tales acciones se regirán por la normativa que en cada caso resulte de aplicación. Los particulares perjudicados no podrán exigir reparación ni indemnización por los daños medioambientales que se les hayan irrogado, en la medida en la que tales daños queden reparados por la aplicación de esta Ley. El responsable que hubiera hecho frente a esa doble reparación podrá reclamar del perjudicado la devolución o la compensación que proceda. En ningún caso las reclamaciones
} 
suelo y especies silvestres) de titularidad privada con independencia de la legitimación para reclamar su reparación ${ }^{9}$.

\section{a) Características del daño ambiental}

Junto a esta delimitación legal del concepto de daño ambiental debemos señalar que entre las características más significativas del mismo se ha destacado que es irreversible, acumulable, difuso, colectivo, carece de espacialidad determinada y es circunstancialmente irreparable ${ }^{10}$. Precisamente esa dificultad en la reparación del daño ambiental ha llevado a la jurisprudencia del Tribunal Supremo a priorizar la reparación en especie o in natura y sólo cuando ésta no sea posible se acude a la indemnización de los daños y perjuicios ${ }^{11}$.

No cabe duda que el daño ambiental no sólo afecta a bienes de naturaleza pública como el equilibrio propio de los ecosistemas, la biodiversidad, y la salud en general, sino que en muchas ocasiones perjudica también los derechos subjetivos e intereses legítimos de una pluralidad de sujetos, los cuales pueden ser de fácil o difícil individualización, dependiendo del tipo y gravedad del daño acontecido, pero en la mayoría de los casos, la que se ve afectada es la propia comunidad al verse vulnerado un interés de naturaleza difusa ${ }^{12}$.

de los particulares perjudicados en cualesquiera procesos o procedimientos exonerarán al operador responsable de la adopción plena y efectiva de las medidas de prevención, de evitación o de reparación que resulten de la aplicación de esta Ley ni impedirán las actuaciones administrativas encaminadas a ello.

${ }^{9}$ En efecto, los daños medioambientales que se produzcan sobre elementos de titularidad privada integran la categoría de daños personales, patrimoniales o económicos (los daños a la salud y a la integridad de las personas; los daños a sus bienes y los daños al ejercicio de actividades económicas) y todos ellos están sometidos al ámbito del Derecho privado, donde a priori parece tener perfecta cabida el mecanismo clásico de la responsabilidad civil. Así lo ha defendido, CAFFERATTA, N., "Daño ambiental colectivo y proceso civil colectivo" Ley 25675, Revista de Responsabilidad civily Seguros, Año V, No II, marzo - abril 2003.

${ }^{10}$ VÁZQUEZ GARCÍA, A., "La Responsabilidad por Daños al Ambiente", Memorias del Segundo Encuentro Internacional de Derecho Ambiental, México, 2004, y BLANCO LOZANO, C., "Víctima y Reparación en el Delito Ambiental", Revista de Derecho Ambiental, n ${ }^{\circ}$ 18, 1997.

${ }^{11}$ Vid. SSTS de 20 de enero y 5 de febrero de 1916; 23 de septiembre y 27 de octubre de 1988. En la STS de 23 de septiembre de 1988, por ejemplo, en un caso de contaminación de las aguas de un pozo de la finca del demandante, por las filtraciones originarias del daño de la balsa de la parte demandada, se impone a la parte recurrida la obligación de las labores de limpieza necesarias para restablecer las aguas del pozo a su estado de pureza original; y en la STS de 1 de marzo de 1993, con ocasión de un daño por contaminación derivada de gas y polvo arcilloso, se afirma que la finalidad única de la acción de responsabilidad extracontractual es la de obtener la reparación íntegra de los perjuicios causados, que se subsumen tanto en el daño emergente como en el lucro cesante, condenándose a los demandados al pago del importe de los gastos de regeneración de la finca y las derivaciones definitivas que pudieran existir.

${ }^{12}$ El daño ambiental es difuso, no solo por la dificultad que entraña identificar a los agentes que lo causan, sino también, por la determinación de los sujetos que se encuentran legitimados para entablar accio- 
Además, los efectos sobre la salud y el medio ambiente causado por las alteraciones realizadas por el ser humano son generalmente desconocidos y en algunas ocasiones difíciles o imposibles de conocer. De ahí el reconocimiento del principio precautorio propio del derecho ambiental, contenido en múltiples instrumentos internacionales ${ }^{13}$, y por medio del cual se establece como regla que cuando exista peligro de daño grave o irreversible, la falta de certeza científica absoluta no puede utilizarse como razón para no adoptar medidas eficaces que impidan la degradación del ambiente.

Por otro parte, el daño ambiental puede llegar a ser expansivo en tanto que el hecho causante genera unos efectos que llegan a convertirse en nuevas causas generadoras de otro tipo de daños, ocasionándose por tanto, una cadena que a la postre, podría llegar a ser interminable, afectando de esta forma una multiplicidad de recursos ${ }^{14}$. Es así como los elementos que producen molestias pueden ser difusos y lentos, sumarse y acumularse entre sí y son susceptibles de producir efectos a grandes distancias. La concurrencia de varios agentes contaminantes, en muchas ocasiones hace difícil la apreciación de la relación de causalidad en los términos tradicionales del concepto. Asimismo, el daño am-

nes judiciales o administrativas ante los órganos competentes, así como aquellos a los que puede alcanzar una posible indemnización. Como establece PEÑA CHACÓN, M, "La Legitimación Procesal en el Derecho Ambiental”, Revista Jurídica Lex difusión y análisis, año VII, marzo 2003, número 93, Editora Laguna, México, y en Revista de Direito Ambiental, año 8, enero-marzo 2003, número 29, Editorial Dos Tribunais, Brasil, "Los intereses difusos no entran en la categoría de los intereses legítimos o en los derechos subjetivos, tampoco encajan en la categoría de intereses colectivos o corporativos. No son ni enteramente públicos, ni enteramente privados, sino que se encuentran compuestos de ambas manifestaciones. Son de todos y de ninguno, pues a todos compete su defensa y tutela, sin que pueda pretenderse su monopolio procesal. Los intereses difusos pertenecen a todos y a cada uno de los miembros de grupo, clase, comunidad, sin que medie la existencia de un vínculo jurídico determinado. Se diferencian de los intereses colectivos en que estos últimos son típicos intereses de grupos organizados, imputables por tanto a colectividades organizadas como un todo, sea mediante asociaciones, organizaciones o grupos organizados, mientras que los intereses difusos no se encuentren unificados en una colectividad organizada, sino que se encuentren diseminados en una generalidad heterogénea e indeterminada de sujetos".

${ }^{13}$ El principio precautorio fue incluido por primera vez en la Ley contra la Contaminación Atmosférica de la República Federal Alemana del año 1974, para luego ser incorporada en instrumentos internacionales como la Conferencia Internacional sobre la Protección del Mar del Norte; Protocolo de Montreal sobre sustancias que debilitan la capa de ozono; Declaración Ministerial de Bergen sobre desarrollo sostenible en la Comunidad Europea; Declaración de Río sobre Medio Ambiente y Desarrollo; Convenio Marco de Cambio Climático; Tratado de Maastrich y Amsterdam en los que se constituye la Unión Europea; Protocolo de Cartagena sobre seguridad de la biotecnología del Convenio sobre Biodiversidad; la Convención de Estocolmo para la eliminación de contaminantes orgánicos persistentes y el Acuerdo sobre la Aplicación de las Disposiciones de la Convención de las Naciones Unidas sobre el Derecho del Mar relativas a la Conservación y Ordenación de las poblaciones de Peces Tranzonales y las Poblaciones de Peces Altamente Migratorias.

${ }^{14}$ González, Rafael, "Recomendaciones para la caracterización del daño ambiental" en Temas de Derecho Ambiental, Editorial Investigaciones Jurídicas S.A., 2001, Costa Rica. 
biental puede ser también concentrado o diseminado, siendo el primero aquel tipo de daño cuya fuente es fácilmente identificable derivado de un suceso discreto o continuo, mientras que el daño diseminado o difuso, se presenta cuando existe una multiplicidad de fuentes productoras del daño, esparcidas territorialmente, siendo su identificación e individualización de gran dificultad.

Desde un punto de vista temporal el daño ambiental se podría catalogar como de continuado, permanente o bien progresivo. El daño continuado es aquel que es producto de un proceso dilatado en tiempo, y por lo tanto su desarrollo no es consecuencia de una única acción localizable en el tiempo, sino que es obra de un conjunto o sucesión de actos, de un mismo o varios autores, en épocas diversas. Si los efectos del daño ambiental continúan en el tiempo, estaríamos en presencia de un daño permanente. Por su parte, daño progresivo es aquel que es producto de una serie de actos sucesivos, cuya conjugación provoca un daño mayor que la suma de cada uno de los daños individualmente generados por cada acto lesivo; es lo que los científicos denominan procesos de saturación.

En definitiva, tal y como expone CAFFERATTA ${ }^{15}$, la agresión medioambiental puede ser desparramada, difusa, cambiante, traslaticia, nómada, itinerante, difícilmente contenible, viajera, mutante, desconcertante, sin límites geográficos, temporales, ni personales, potencialmente expansiva, multiplicadora, en ocasiones con efectos retardatorio, progresivo, acumulativo, sinérgico, invisible, silencioso, mortal o altamente riesgoso, explosivo o tóxico, degradante, capaz de provocar en su camino o desarrollo múltiples daños, supraindividuales y/o individuales, de afectación patrimonial o extrapatrimonial en derechos de la salud o en derechos personalísimos y/o coparticipados, insignificantes o pequeños hasta verdaderos desastres o estragos de efectos impredecibles.

Por tanto, estas características especiales distinguen el daño ambiental de los daños tradicionales, pues no se cumplen los elementos básicos del derecho de daños, según el cual, éste debe ser siempre cierto, efectivo, determinable, evaluable, individualizable y no puramente eventual o hipotético. Tratándose del daño ambiental, sólo es necesario su probabilidad futura para determinar su existencia y tomar las medidas necesarias con el fin de impedir sus efectos nocivos.

15 "Prueba y nexo de causalidad en el Daño Ambiental", en obra colectiva Meio Ambiente e Acceso à fustiça. Homenagem a Vladimir PASSOS DE FREITAS, Volumen 3, $11^{\circ}$ Congreso Internacional de Direito Ambiental, 27 de Maio a $1^{\circ}$ de Junho de 2007, Sao Paulo, Brasil, Instituto O Direito po um Planeta Verde, Imprenta Oficial do estado de Sao Paulo. 


\section{b) Agente causante del daño}

Por lo que respecta al régimen jurídico del potencial agente causante del daño, debemos señalar que el agente causante del daño ambiental es el operador que realiza alguna de las actividades económicas o profesionales recogidas en el anexo III de la $\mathrm{Ley}^{16}$.

Los operadores de cualquier actividad están obligados a adoptar las medidas preventivas apropiadas ante una amenaza inminente de daños medioambientales originada por su actividad (medidas de prevención), así como las medidas apropiadas de evitación de nuevos daños cuando se hayan producido daños medioambientales por su actividad (medidas de evitación), aun cuando en la causación del daño o de la amenaza inminente no haya concurrido dolo, culpa o negligencia ${ }^{17}$. Sin embargo, cuando el daño medioambiental o su amenaza inminente proviene de una de las actividades enumeradas en el Anexo III de la LRM, el operador de dicha actividad queda obligado a adoptar, además, las medidas que resulten oportunas para reparar, restaurar o remplazar los recursos naturales afectados, aun cuando en la causación del daño o de la amenaza inminente no haya concurrido dolo, culpa o negligencia. De igual forma, quedarán obligados a adoptar medidas de reparación los operadores de cualquier actividad que causen un daño como consecuencia del incumplimiento de los deberes relativos a las medidas de prevención y evitación de daños, o bien como consecuencia de una actuación dolosa o culposa ${ }^{18}$.

\section{c) Medidas reparadoras del daño ambiental}

Las medidas de reparación en caso de producirse un daño ambiental tienen por objeto restituir el recurso natural a su estado básico a través de medidas

\footnotetext{
${ }^{16} \mathrm{El}$ anexo III enumera las actividades a que hace referencia el artículo 3.1de la Ley: la explotación de instalaciones sujetas a una autorización de conformidad con la Ley 16/2002, de 1 de julio, de Prevención y Control Integrados de la Contaminación; las actividades de gestión de residuos, como la recogida, el transporte, la recuperación y la eliminación de residuos y de residuos peligrosos, así como la supervisión de tales actividades, que estén sujetas a permiso o registro de conformidad con la Ley 10/1998, de 21 de abril; todos los vertidos en aguas interiores superficiales sujetas a autorización previa de conformidad con el Real Decreto 849/1986, de 11 de abril, por el que se aprueba el Reglamento del Dominio Público Hidráulico y la legislación autonómica aplicable; todos los vertidos en las aguas subterráneas sujetas a autorización previa de conformidad con el Real Decreto 849/1986, de 11 de abril, y la legislación autonómica aplicable, etc.

17 Art. 17 LRM.

18 Art. 19 LRM.
}

Revista Andaluza de Administración Pública

ISSN: 0034-7639, núm. 81, Sevilla, septiembre-diciembre (2011), págs. 47-100 
primarias, complementarias y compensatorias. Por tanto, cuando se hayan producido daños medioambientales, el operador, sin demora y sin necesidad de advertencia, de requerimiento o de acto administrativo previo, adoptará todas aquellas medidas provisionales necesarias para, de forma inmediata, reparar, restaurar o reemplazar los recursos naturales y servicios de recursos naturales dañados, de acuerdo con los criterios previstos en el anexo II (art. 20 LRM), que determina que la reparación primaria es toda medida correctora que restituya o aproxime al máximo los recursos naturales o servicios de recursos naturales dañados a su estado básico; la reparación complementaria es toda medida adoptada para compensar el hecho de que la reparación primaria no haya dado lugar a la plena restitución de los recursos naturales o servicios de los recursos dañados; y la reparación compensatoria es toda acción adoptada para compensar las pérdidas provisionales de recursos naturales o servicios de recursos naturales que tengan lugar desde la fecha en que se produjo el daño hasta el momento en que la reparación primaria haya surtido todo su efecto.

Cada medida primaria, complementaria y compensatoria tiene una finalidad en la reparación del daño. Así, la finalidad de la reparación primaria es restituir o aproximar los recursos naturales o los servicios de recursos naturales dañados a su estado básico; la finalidad de la reparación complementaria es proporcionar un nivel de recursos naturales o servicios de recursos naturales, inclusive, si procede, en un lugar alternativo similar al que se habría proporcionado si el lugar dañado se hubiera restituido a su estado básico, cuando la reparación primaria no lo ha conseguido; y la finalidad de la reparación compensatoria es compensar la pérdida provisional de recursos naturales y servicios de recursos naturales durante la recuperación. Esta reparación compensatoria consiste en aportar mejoras adicionales a las especies silvestres y los hábitats o a las aguas, ya sea en el lugar dañado o en un lugar alternativo, y no en compensar económicamente al público.

Llegados a este punto, podemos afirmar que para reparar el daño ambiental tienen que darse los siguientes elementos fundamentales:

a) Un agente causante del daño: los operadores que realizan actividades económicas o profesionales recogidas en el anexo III.

b) Existencia de un daño real y cuantificable.

c) Relación de causalidad daño-agente, salvo que se trate de las actividades recogidas en el Anexo III, en cuyo caso se da una presunción de imputación cuando atendiendo a la naturaleza intrínseca de la actividad o a la forma en la que ha sido desarrollada sea apropiada para haber causado el daño o amenaza. 


\section{Carencias del sistema de responsabilidad medioambiental}

El sistema de responsabilidad medioambiental establecido en la LRM delimita, como hemos visto, el daño ambiental, introduce el régimen jurídico del potencial agente causante del daño y regula las medidas de reparación en caso de producirse un daño o una amenaza inminente de daño, pero, sin embargo, no establece los criterios a seguir para valorar el daño una vez producido. Por tanto, y al margen de los criterios establecidos por el legislador ambiental para determinar el daño ambiental, desconocemos las normas y posibles métodos de valoración a utilizar para cuantificar el daño a los bienes ambientales.

En el mismo sentido, la legislación ambiental internacional no establece, con carácter general, disposiciones donde se recojan, aún someramente, criterios estandarizados de valoración del daño ambiental. Tras realizar un análisis de la legislación ambiental existente, tan sólo hemos encontrado preceptos dispersos que reconocen la necesidad de indemnizar el daño ambiental, pero no se establecen soluciones al cálculo de la citada indemnización. Así, por ejemplo, la Ley de Bases Generales del Ambiente de Chile ${ }^{19}$, la Ley General del Medio Ambiente de Nicaragua ${ }^{20}$, la Ley de Medio Ambiente del El Salvador ${ }^{21}$ o la Directiva 2004/35/CE del Parlamento Europeo y del Consejo, de 21 de abril de 2004, sobre Responsabilidad Ambiental en relación con la Prevención y Reparación de Daños Ambientales ${ }^{22}$. Estos son sólo algunos ejemplos normativos, pues con carácter general todas las legislaciones medioambientales de los diferentes Estados tienen un precepto en dicho sentido.

${ }^{19}$ Artículo 3: Sin perjuicio de las sanciones que señale la Ley, todo el que culposa o dolosamente cause daño al medio ambiente, estará obligado a repararlo materialmente a su costo, si ello fuera posible, e indemnizarlo de conformidad a la ley.

${ }^{20}$ Artículo 143: Cuando en la comisión del hecho participen dos o más personas, éstas serán responsables solidariamente de la totalidad de los daños y perjuicios económicos causados.

${ }^{21}$ Artículo 5: Para los efectos de esta Ley y su Reglamento se entenderá por obligación de reparar el daño, el deber legal de restablecer el medio ambiente o ecosistema, a la situación anterior al hecho que lo contaminó, deterioró o destruyó, cuando sea posible, o en dar una compensación a la sociedad en su conjunto que sustituya de la forma más adecuada y equitativa el daño, además de indemnizar a particulares por perjuicios conexos con el daño ambiental, según corresponda.

${ }^{22}$ Que establece que se exigirá al operador que sufrague los gastos derivados de la ejecución de las medidas preventivas y/o reparadoras, salvo que demuestre que:

a) Los daños fueron causados por un tercero y a pesar de las medidas de seguridad existentes.

b) Los daños se produjeron como consecuencia del cumplimiento de una orden o instrucción obligatoria por parte de una autoridad pública.

Revista Andaluza de Administración Pública

ISSN: 0034-7639, núm. 81, Sevilla, septiembre-diciembre (2011), págs. 47-100 
En nuestro ordenamiento jurídico es el artículo 9 de la LRM el que establece que los operadores de las actividades económicas o profesionales están obligados a adoptar y a ejecutar las medidas de prevención, de evitación y de reparación de daños medioambientales y a sufragar sus costes, cualquiera que sea su cuantía, cuando resulten responsables de los mismos. Quizás por ello, se regulan los criterios de determinación de la obligación de reparación de los daños medioambientales que además deben ser aplicados no sólo en un procedimiento administrativo, sino en cualquier proceso judicial, ya sea civil, penal o contencioso-administrativo. Pero no se establecen los criterios a seguir en dichos procesos para valorar y cuantificar el daño ambiental. Es por ello que entendemos necesario centrarnos en el análisis de este elemento del sistema de responsabilidad medioambiental.

\section{DETERMINACIÓN Y VALORACIÓN DEL DAÑO AMBIEN- TAL}

La ausencia de pautas normativas para valorar y cuantificar el daño ambiental en nuestro ordenamiento jurídico no nos impide poder extraer de la legislación ambiental algunos criterios necesarios en la valoración del daño ambiental, si bien es cierto, como vamos a ver, que se trata de unos criterios valorativos dispersos en la LRM y su Reglamento de desarrollo, que atienden más a la determinación del daño que a la valoración del mismo y que por tanto, entendemos que son insuficientes a la hora de cuantificar el daño ambiental y el coste de las medidas reparadoras.

\section{Los criterios para determinar el daño ambiental establecidos por el legislador ambiental}

Entre los criterios valorativos que derivan de la LRM podemos señalar el establecimiento de los criterios para evaluar el carácter significativo del daño cuando éste produzca efectos desfavorables en la posibilidad de alcanzar o de mantener el estado favorable de conservación de las especies o los hábitats. Para ello, se evaluará en relación con el estado de conservación que tuvieran al producirse el daño, con las prestaciones ofrecidas por las posibilidades recreativas que generan y con su capacidad de regeneración natural. Los cambios adversos significativos en el estado básico deberán determinarse mediante datos mensurables como: a) el número de individuos, su densidad o la extensión de su zona de presencia; b) la rareza de la especie o del hábitat dañado (evaluada en el plano local, regional y superior, incluido el plano comunitario), así como 
su grado de amenaza; c) el papel de los individuos concretos o de la zona dañada en relación con la especie o la conservación de su hábitat; d) la capacidad de propagación y la viabilidad de la especie (según la dinámica específica de la especie o población de que se trate) o la capacidad de regeneración natural del hábitat (según la dinámica específica de sus especies características o de sus poblaciones) dañados; y e) la capacidad de la especie o del hábitat, después de haber sufrido los daños, de recuperar en breve plazo, sin más intervención que el incremento de las medidas de protección, un estado que, tan sólo en virtud de la dinámica de la especie o del hábitat, dé lugar a un estado equivalente o superior al básico ${ }^{23}$.

No obstante, para determinar el carácter significativo del daño medioambiental, el operador debe identificar el agente causante del daño, y los recursos naturales y servicios afectados; cuantificar el daño y evaluar la significatividad del daño ${ }^{24}$.

En cuanto al agente causante del daño, éste puede ser químico (asociado a la liberación de una sustancia en una concentración superior al umbral de toxicidad de dicha sustancia en determinado medio receptor), físico (referido al exceso o defecto de una sustancia que no tiene asociado un nivel de toxicidad, tales como el agua, los residuos inertes, la tierra, la temperatura o los campos electromagnéticos) o biológico (entre otros, los organismos modificados genéticamente, las especies exóticas invasoras y los microorganismos patógenos).

Por lo que respecta a la identificación de los recursos naturales y servicios afectados, se deberá analizar por el operador todos los recursos naturales afectados por el agente causante del daño de forma directa o indirecta. En particular, se realizará un análisis de los recursos más vulnerables o sensibles a la

\footnotetext{
${ }^{23}$ En cualquier caso, los daños con efectos demostrados en la salud humana deben clasificarse como daños significativos. En cambio, no tienen el carácter de daños significativos: a) las variaciones negativas inferiores a las fluctuaciones naturales consideradas normales para la especie o el hábitat de que se trate; b) las variaciones negativas que obedecen a causas naturales o se derivan de intervenciones relacionadas con la gestión corriente de los espacios naturales protegidos o los lugares de la Red Natura 2000, según se definan en sus respectivos planes de gestión o instrumentos técnicos equivalentes; c) los daños a especies o hábitat con demostrada capacidad de recuperar, en breve plazo y sin intervención, el estado básico o bien un estado que, tan sólo en virtud de la dinámica de la especie o del hábitat, dé lugar a un estado equivalente o superior al básico. Véase anexo I de la LRM.

${ }^{24}$ Según se establece en el art. 7 del RD 2090/2008, de 22 de diciembre, por el que se aprueba el Reglamento de desarrollo parcial de la Ley 26/2007, de 23 de octubre, de Responsabilidad Medioambiental.
} 
modificación de su entorno o que afecten a la estabilidad del ecosistema. Asimismo, se identificará el nivel de provisión de servicios que proporcionan los recursos naturales afectados.

La cuantificación del daño consistirá en estimar el grado de exposición por parte de los receptores afectados al agente causante del daño y en la medición de los efectos que éste produce sobre aquéllos. Para cuantificar el daño los operadores identificarán, describirán y evaluarán la extensión ${ }^{25}$, la intensidad ${ }^{26}$ y la escala temporal del daño ${ }^{27}$.

La evaluación de la significatividad del daño requerirá, por su parte, del análisis de la variación que hayan experimentado, entre otros, los siguientes parámetros:

a) El estado de conservación del recurso afectado.

b) El estado ecológico, químico y cuantitativo del recurso afectado.

c) La integridad física del recurso afectado.

d) El nivel de calidad del recurso afectado.

e) Los riesgos para la salud humana o para el medio ambiente asociados al recurso afectado.

Una vez determinado el carácter significativo del daño ambiental, la propia LRM establece el marco común que habrá de seguirse a fin de elegir las medidas más adecuadas para garantizar la reparación del daño medioambien$\mathrm{tal}^{28}$. Resultan significativas las técnicas de valoración que utiliza el legislador para identificar las medidas reparadoras primarias, complementarias y compensatorias. Así, en primer lugar se atiende a la utilización de criterios de equivalencia recurso-recurso o servicio-servicio. De acuerdo con estos criterios, se considerarán preferentes acciones que proporcionen recursos naturales o servicios de recursos naturales del mismo tipo, calidad y cantidad que los daña-

\footnotetext{
${ }^{25}$ Según el art. 12 del Reglamento de desarrollo parcial de la LRM, la extensión del daño se determinará mediante la medición de la cantidad de recurso o de servicio afectado. En su determinación se tendrán en cuenta las siguientes circunstancias: a) las propiedades del agente causante del daño; b) las características del medio receptor; c) cualquier cambio que los medios de difusión y receptores pudieran experimentar debido a la acción del agente causante del daño.

${ }^{26}$ Según el art. 13 del Reglamento de desarrollo parcial de la LRM, la intensidad del daño se estima mediante el establecimiento del grado de severidad de los efectos ocasionados por el agente causante del daño a los recursos naturales o servicios afectados y a las especies clave de los recursos naturales afectados.

${ }^{27}$ Según el art. 14 del Reglamento de desarrollo parcial de la LRM, para determinar la escala temporal del daño se estimará la duración, la frecuencia y la reversibilidad de los efectos que el agente causante del daño ocasiona sobre el medio receptor.

${ }^{28}$ Véase el anexo II LRM.
} 
dos. Si esto no fuera posible, se proporcionarán recursos naturales o servicios de recursos naturales alternativos (por ejemplo, una disminución de la calidad podría compensarse con un aumento del número de medidas reparadoras). En segundo término, y siempre que no sea posible utilizar criterios preferentes de equivalencia recurso-recurso o servicio-servicio, se aplicarán técnicas de valoración alternativas, siguiendo criterios de equivalencia valor-valor o valor-coste. En efecto, si es posible valorar los recursos naturales o servicios de recursos naturales perdidos pero no es posible valorar los recursos o servicios de reposición en un plazo o con unos costes razonables, se podrá optar por medidas reparadoras cuyo coste sea equivalente al valor monetario aproximado de los recursos naturales o servicios de recursos naturales perdidos.

Estos elementos valorativos y delimitadores del daño ambiental regulados por la LRM, hay que complementarlos con la reciente aprobación por el Ministerio de Medio Ambiente, Medio Rural y Marino de la metodología del Modelo de Oferta de Responsabilidad Ambiental (MORA) ${ }^{29}$ para la estimación de los costes de reposición de los recursos naturales, elaborada por la Comisión Técnica de Prevención y Reparación de Daños Medioambientales ${ }^{30}$.

El Modelo de Oferta de Responsabilidad Ambiental (MORA) proporciona una herramienta de monetización de daños acorde con los requerimientos de la normativa de responsabilidad medioambiental. Así, los daños ocasionados a los recursos naturales se evalúan con métodos económicos de oferta, a través de su correspondiente coste de reposición, bajo un enfoque de equivalencia del tipo recurso-recurso, establecido en la LRM con carácter preferente.

\section{Métodos de valoración económica del daño ambiental}

El análisis de la valoración del daño ambiental quedaría incompleto si ante la falta de una normativa clara y concisa sobre esta cuestión, no recogemos algunos de los métodos de valoración del daño ambiental establecidos por la

\footnotetext{
${ }^{29}$ Aprobado el 13 de abril de 2011 en la Quinta Reunión de la Comisión Técnica de Prevención y Reparación de Daños Medioambientales.

${ }^{30}$ Esta Comisión Técnica de Prevención y Reparación de Daños Medioambientales es un órgano de cooperación técnica y colaboración entre la Administración General del Estado y las comunidades autónomas para el intercambio de información y el asesoramiento en materia de prevención y de reparación de los daños medioambientales, y fue creada mediante el Reglamento de desarrollo parcial de la Ley 26/2007, aprobado mediante el Real Decreto 2090/2008.
} 
doctrina desde una perspectiva más economista que jurídica y que son los que se utilizan en la práctica a la hora de valorar el coste económico de un daño ambiental $^{31}$.

Como punto de partida es preciso señalar que todos lo métodos utilizados se caracterizan por poner el acento en el valor económico del bien natural ${ }^{32}$. Así, los métodos generalmente más usados son los siguientes:

a) Método del precio de mercado. El valor se estima a partir del precio que tiene el bien en el mercado. Es la forma más usual de valorar o cuantificar el daño ambiental aunque plantea bastantes problemas pues no siempre es posible atribuir un valor de mercado al recurso natural y en ocasiones el valor de mercado no es el valor real de un bien ambiental.

b) Método de reemplazo o sustitución. El valor se infiere del coste de la reparación del bien. Así se puede estimar por ejemplo el coste de la eliminación de una sustancia contaminante de un embalse de agua a partir del coste de la construcción y el funcionamiento de una depuradora de agua.

c) Método de la estimación del precio hedónico. Se utiliza cuando los valores de los bienes ambientales afectan en el precio de los bienes que se comercializan entorno a ellos. Así, por ejemplo, una casa con vistas panorámicas a paisajes tendrá más valor que otra que no las tenga.

d) Método del costo de viaje. Es un método que atiende al valor del bien ambiental a partir de la suma de dinero que desembolsan las personas para llegar al lugar donde se encuentra el bien.

\footnotetext{
${ }^{31}$ Sobre los métodos de valoración económica del daño ambiental pueden consultarse, entre otros: CASIMIRO HERRUZO, A., "Fundamentos y métodos para la valoración de bienes ambientales", Jornada Temática: Aspectos Medio Ambientales de la Agricultura, Libro Blanco de la Agricultura y el Desarrollo Rural, Madrid, 2002; CASTAÑÓN DEL VALLE, M., Valoración del daño ambiental, Programa de las Naciones Unidas para el Medio Ambiente (PNUMA), 2006; LEAL, J., "Técnicas de Valorización Económica de Impactos Ambientales: Aplicabilidad en el caso del sector minero", p. 1-23, Revista del CIPMA, Chile, Marzo 2000; LINARES LLAMAS, P. y ROMERO PÉREZ, C., "Economía y Medio Ambiente: herramientas de valoración ambiental", en la obra coordinada por BECKER ZUAZUA, F., CAZORLA PRIETO L.M, y MARTÍNEZ-SIMANCAS SÁNCHEZ, J., Tratado de Tributación Medioambiental, págs. 1189-1225. Aranzadi, Gizur Menor. 2008; PEÑA CHACÓN, M., "Reparación y valoración económica de los daños causados al medio ambiente", Medio Ambiente y Derecho, Revista Electrónica de Derecho Ambiental, no 12-13, 2005.

32 Podemos señalar como ejemplo normativo el Decreto 4/1986, de 22 de enero, por el que se amplía la lista de especies protegidas y se dictan normas para su protección en el territorio de la Comunidad Autónoma de Andalucía, en cuyo anexo atribuye una valoración económica a determinadas especies de mamíferos, aves, reptiles y anfibios.
} 
e) Método de la transferencia de beneficios. El valor económico del bien se calcula transfiriendo las estimaciones de valores existentes realizadas en estudios ya completados en relación a otros bienes similares.

f) Método de valoración contingente. Consiste en la realización de encuestas a la población en las que se les pregunta cuánto están dispuestas a pagar por un bien o servicio ambiental.

g) Método de la productividad. Se estima el valor económico de productos o servicios ambientales que contribuyen a la obtención de bienes comercializables.

Estos métodos se utilizan para determinar el valor económico del bien o servicio ambiental, el cual se mide en función a lo que se está dispuesto a pagar por ese bien. Es decir, se realiza con base en el beneficio que aporta a la sociedad. En este sentido, la valoración de bienes ambientales atiende al valor de uso y al valor de no uso ${ }^{33}$.

El Valor de uso, que se divide a su vez en:

- Valor de uso directo. Se reconoce de manera inmediata a través del consumo del recurso o de su recepción por los individuos.

- Valor de uso indirecto. Se refiere a los beneficios que recibe la sociedad a través de los servicios ambientales de los ecosistemas y de las funciones de los hábitats.

- Valor de opción. Se refiere al valor de los usos potenciales de los recursos biológicos para su utilización futura.

El Valor de no uso, que incluye a su vez:

- Valor de herencia. Se refiere al valor de legar los beneficios del recurso a las generaciones futuras.

- Valor de existencia. Es el valor de un bien ambiental simplemente porque existe.

Para medir el valor económico se pueden usar diferentes tipos de mercado. Así, usando un mercado real se tendrá en cuenta el precio de mercado como índice del valor monetario del recurso biológico y sobre el precio de mercado se calcula el cambio de productividad que se produce cuando se pierde productividad. En un mercado sustitutivo se utiliza la información de precios de mercados

\footnotetext{
33 Véase, DE ALBA, E. y REYES, M. E., "Valoración económica de los recursos biológicos del país", en la obra La Diversidad Biológica de México: Estudio de País 1998, Conabio, Comisión Nacional para el Conocimiento y Uso de la Biodiversidad, México, 1998.
} 
reales para calcular, de modo estimado, el valor monetario de los recursos ambientales para los que no existe mercado. $\mathrm{Y}$ en un mercado simulado la técnica más empleada es el método de valoración contingente que, como hemos visto, consiste en realizar a la población una encuesta en la que se le pregunta cuánto estaría dispuesta a pagar por un bien ambiental determinado.

Los problemas que plantea esta metodología de valoración del daño ambiental residen en la falta de idoneidad de alguno de ellos. A lo sumo, podría optarse por una utilización conjunta de los diferentes métodos de valoración para no dejar ningún elemento del daño ambiental sin valorar. Pero incluso aunque los métodos se utilicen de forma conjunta se cae en el error de dar un valor monetario a los bienes ambientales cuando éstos representan otros valores que no tienen respuesta económica como son los valores estéticos, morales y funcionales o instrumentales, ya señalados por la Organización para la Cooperación Económica y el Desarrollo (OCDE) en $2002^{34}$.

Estos otros valores que deben tenerse en cuenta al establecer criterios válidos para la valoración del daño ambiental formarían parte de lo que se ha venido a denominar el valor intrínseco del bien ambiental al que los científicos de la economía ecológica hacen referencia y que no se puede cuantificar ${ }^{35}$. En efecto, cuando hablamos de la valoración del medio ambiente en realidad a lo que estamos haciendo referencia es a la valoración no del medio ambiente en sí, sino de las preferencias de la gente por los cambios positivos o negativos en la calidad de su medio ambiente. Sin embargo, el valor intrínseco de los recursos, bienes y servicios ambientales es un valor "en sí", que no coincide con los valores o preferencias de los individuos. La economía del medio ambiente acepta actualmente que ambas posibilidades existen, y que la valorización comporta dos cuestiones bien diferentes: el valor de las preferencias del público a favor o en contra los cambios en la calidad ambiental (valor económico), y el valor que existe intrínsecamente al "interior" de los recursos del medio ambiente (valor intrínseco).

\footnotetext{
${ }^{34}$ En su Manual de Valoración de la Biodiversidad. Handbook of Biodiversity Valuation. A Guide for Policy Makers, OECD, 2002.

${ }^{35}$ En este sentido, véase ARRIBAS HERGUEDAS, F., "Del valor intrínseco de la naturaleza", Revista Isegoría. Consejo Superior de Investigaciones Científicas, Núm. 34, 2006, págs. 261-275; CASIMIRO HERRUZO, A., "Fundamentos y métodos para la valoración de bienes ambientales", Jornada Temática: Aspectos Medio Ambientales de la Agricultura, Libro Blanco de la Agricultura y el Desarrollo Rural, Madrid, 2002; LEAL, J., "Técnicas de Valorización Económica de Impactos Ambientales: Aplicabilidad en el caso del sector minero", p: 1-23, Revista del CIPMA, Chile, Marzo 2000.
} 
La diferencia más sustantiva entre el valor económico y el valor intrínseco es que el primero puede ser medido y, por tanto, utilizado en el contexto del análisis económico de las cuestiones ambientales, mientras que el segundo no puede ser medido, sólo estimado parcialmente. Así, mientras que el valor económico puede cambiar y evolucionar con el tiempo debido a cambios en el hábito, la cultura, y por lo tanto en la demanda por bienes ambientales, el valor intrínseco es un valor fijo. No obstante, algún componente de las preferencias humanas respecto al medio natural creemos que podría captar, al menos en parte, el valor intrínseco de los bienes ambientales. Nos estamos refiriendo al valor de no-uso al que antes hacíamos referencia y que tiene en cuenta valores como el de herencia o legado y el de existencia que no atienden a las preferencias humanas sobre ellos y que son una fuente potencial de valor económico aunque no estén relacionados con el uso directo de un bien ambiental ${ }^{36}$.

Por tanto, la valoración económica ambiental entendida como la búsqueda de la curva de demanda para los recursos, bienes y servicios ambientales, es decir, el valor que los seres humanos dan al medio ambiente, expresado en términos monetarios por su disposición a pagar por los cambios en la calidad ambiental, presenta el problema de la determinación de qué valores deberían informar y guiar el proceso de toma de decisiones públicas. Entendemos que tanto el valor económico como el valor intrínseco son legítimos y relevantes para el proceso de toma de decisiones, pues el tomar decisiones sobre la única base de los valores económicos, no refleja de manera adecuada el proceso que se da en el mundo real, ni tampoco es apropiado cuando es obvio que los agentes involucrados en el desarrollo tienen múltiples objetivos, y no solamente los económicos.

\footnotetext{
${ }^{36}$ Como ejemplo de valoraciones de bienes ambientales que reflejan el valor intrínseco del bien podemos señalar la Norma Granada 1990 (revisada en 1999 y en 2006), auspiciada por la Asociación Española de Parques y Jardines Públicos, sobre valoración del arbolado ornamental que cumple acciones beneficiosas (depuración del aire, amortiguación del ruido, modificación del microclima urbano, efectos sociales y psicológicos sobre la población, etc.) y cuyas causas de deterioro suelen ser obras, vandalismo o simplemente un mantenimiento incorrecto. Este método de valoración pretende realizar la valoración de los árboles con interés paisajístico reflejando su cuantía de utilidad de un modo monetario a través de un modo de valoración equilibrada, en la que se combinan intereses no sólo económicos sino también paisajísticos, históricos y estéticos, entre otros. Esta norma de valoración ambiental es ampliamente utilizada en España e Iberoamérica debido a su gran prestigio.
}

Revista Andaluza de Administración Pública

ISSN: 0034-7639, núm. 81, Sevilla, septiembre-diciembre (2011), págs. 47-100 


\section{EL PAPEL DE LA JURISPRUDENCIA INTERNACIONAL EN LA EVOLUCIÓN DEL CONCEPTO DE DAÑO AMBIENTAL Y EN LOS PROCEDIMIENTOS PARA SU DETERMINACIÓN Y VALORACIÓN}

Ante la ausencia o insuficiencia de una regulación normativa expresa y completa del daño ambiental y su valoración y determinación, los jueces, de distintas jurisdicciones, han tenido que juzgar casos y asuntos en los que se produjeron graves daños ambientales. Veámos cual fue el tratamiento que dieron al concepto de daño ambiental y cuáles fueron los métodos empleados de valoración y determinación.

\section{El naufragio del Amoco Cádiz}

\section{A. El accidente y su contexto}

El buque petrolero de bandera liberiana Amoco Cádiz que transportaba hacia Rotterdam 227.000 toneladas de petróleo crudo del Golfo Pérsico, derivó hacia la costa bretona en una fuerte tormenta. Durante la tormenta el navío se rompió y naufragó el 16 de marzo de 1978 en aguas francesas, cerca del pueblo de Portsall, en Bretaña. El naufragio se debió a una avería en el sistema de dirección. Del buque salió la totalidad de la carga de petróleo, contaminando unos $375 \mathrm{Kms}$. de costa, destruyendo el 30\% de la fauna y el 5\% de la flora marina, con grave perjuicio para las actividades económicas de la región, consistentes especialmente en la pesca, la ostricultura y el turismo ${ }^{37}$. Numerosas peticiones de resarcimiento fueron presentadas ante un juez estadounidense por numerosos reclamantes, especialmente Francia, los Departamentos y Regiones afectados y diversas personas físicas y jurídicas afectadas ${ }^{38}$.

\footnotetext{
${ }^{37}$ Vid. SCOVAZZI, T. "Amoco Cádiz"; SCOVAZZI, T. "La sentenza sul risarcimento dei danni nel caso Amoco Cádiz", en Rivista Giuridica dell'ambiente, 1988, p. 141; BELLIER, P. and MASSART, G. (1979). The Amoco Cádiz oil spill cleanup operations-an overview of the organisation, control and evaluation of the cleanup techniques employed. Proceedings of the 1979 Oil Spill Conference, 141-146. API Publication $N^{\circ}$. 4308. American Petroleum Institute, Washington, DG, USA; SPOONER, M.F. (editor) (1978). The Amoco Cádiz oil spill. Special edition of Marine Pollution Bulletin 9 (7). Pergamon Press, Oxford and New York; CONAN, G., D'OZOUVIllE, L., and MARCHAND, M. (1978). Amoco Cádiz preliminary observations of the oil spill impact on the marine environment. One day session, Amoco Cádiz, Brest, France, 7 June 1978. Le Centre National pour l'Exploitation des Oceans, París, France.

38 Se eligió el foro norteamericano porque EEUU no había ratificado la Convención sobre la responsabilidad civil por daños de contaminación por hidrocarburos (Bruselas, 29 de noviembre de 1969).
} 
B. El concepto de daño resarcible en el accidente del Amoco Cádiz

Obviando las complicadas cuestiones jurídicas del caso debido a los elementos internacionales del accidente ${ }^{39}$, nos vamos a centrar en ver cuál fue el concepto de daño ambiental que sostuvo el Tribunal que conoció del asusto. El Tribunal que se pronunció, en primera instancia, sobre las categorías de daño y sobre su evaluación pecuniaria fue el Tribunal Northern District of Illinois en su Sentencia de 11 de enero de 1988.

El primer concepto de daño resarcible que tuvo en cuenta el Tribunal fue el de los servicios prestados por los empleados públicos a pesar de la excepción que presentó Amoco, fundamentada en la gratuidad del servicio público, ya que el Estado francés tenía el deber de proteger la salud, el bienestar y la propiedad de sus ciudadanos mediante los servicios de emergencia adecuados cualquiera que fuera la causa que desencadenara la emergencia. A este respecto, el Tribunal rechazó la excepción y afirmó que los servicios prestados por los empleados públicos eran resarcibles sobre la base del valor del tiempo dedicado por ellos a las actuaciones exigidas por el evento dañoso, pero sólo en la medida en que las mismas les hubieran desviado de las otras actividades que normalmente habrían tenido que realizar en razón de sus funciones. Eran resarcibles las prestaciones fuera del horario normal de trabajo, pero no las proporcionadas voluntariamente. Los mismos principios se aplicaron a los servicios prestados por funcionarios elegidos de los municipios. Los gastos de viaje eran resarcibles, si correspondían a las actividades ligadas al incidente.

Fuera del concepto de daño resarcible quedaron: los servicios prestados por voluntarios, que ofrecieron sus prestaciones a los municipios, debiendo reembolsar únicamente el coste de los gastos de alojamiento, comida y transporte de los voluntarios, sufragados por los municipios y las donaciones hechas por los municipios a voluntarios o a militares y los ágapes ofrecidos en su honor.

El Tribunal sí consideraba que debía indemnizarse, en cambio, el coste de los materiales y de los suministros necesarios para las operaciones de intervención, sobre la base de la diferencia entre el precio de compra y el precio residual; en el caso de que se tratara de material ya poseído por los demandantes, la indemnización se determinaría mediante una suma equivalente a la dife-

\footnotetext{
${ }^{39}$ Las cuestiones internacionales se pueden consultar en KISS, "L'affaire de l'Amoco Cádiz: responsabilité pour une catastrophe écologique”, en Fournal de Droit International, 1985, p. 575.
} 
rencia entre el valor inicial y el valor residual, sobre la base del precio razonable de alquiler. El coste de las reparaciones debidas a la utilización de los edificios públicos durante las operaciones también debía ser compensado, así como los gastos por mayor consumo (agua, luz, teléfono). El pago eventual de un alquiler por la utilización de los edificios se realizaría solamente en el caso que se demostrara que, de no haberse dedicado a las tareas vinculadas al accidente, habrían sido destinados a usos productores de beneficios.

Los daños por el restablecimiento de la costa y de los puertos se pagarían a los municipios, a quienes el Estado francés había transferido los derechos relativos a dichos bienes demaniales. A este respecto, los municipios franceses solicitaron una doble reparación, por un lado, a título de pérdida del disfrute, por la incapacidad de realizar sus funciones normales, con una consiguiente pérdida de la calidad de vida de la población de Bretaña, argumentándolo en la imposibilidad de proporcionar playas limpias a los ciudadanos, perturbación de la quietud debido al tráfico intenso generado por las actuaciones; y por otro lado, por la pérdida de imagen, argumentándolo en que las personas que normalmente hubieran visitado estos lugares de vacaciones o con fines de recreo se verían desincentivadas por el deterioro de la reputación de los municipios dañados. Sobre estos puntos el Tribunal fue tajante puesto que, sobre el primer argumento supuso que los servicios públicos esenciales fueron mantenidos, denegando totalmente la compensación por la reducción del nivel de calidad de vida, y, respecto al segundo argumento, sostuvo que el concepto de pérdida de imagen duplicaría los daños pagados a las personas privadas (hosteleros, propietarios de restaurantes, gestores de camping y de otras Actividades), que probaron un perjuicio debido a la disminución del flujo turístico ${ }^{40}$.

Especialmente interesante fue la decisión del Tribunal sobre el daño ecológico. La demanda por la destrucción de especies marinas y la consiguiente pérdida de biomasa fue totalmente rechazada, ya que el Tribunal consideró que nadie estaba legitimado para obtener el resarcimiento por la desaparición de una "res nullius". El Tribunal calificó como no convincente la tesis según la cual el daño reclamado por los municipios no se refería a las especies mismas, sino a la lesión del interés general relativo a la protección de la integridad del dominio público marítimo. El Tribunal dejó claro que el daño ecológico que atañía normalmente al Estado o a los entes públicos, como exponente de un inte-

40 Vid. LUCCHINI, "Le procès de l'Amoco Cádiz: présent el voies de futur", en Annuaire français de Droit International, 1985, p. 762. 
rés general, era diferente del daño por la falta de beneficio, que el Tribunal liquidó a los pescadores privados o a las asociaciones de pescadores que demostraron una reducción en el volumen de las capturas debidas a la contaminación marina. Las demandas referidas a los gastos realizados en planes de repoblación fueron admitidas por el Tribunal. No obstante, el Tribunal dejo constancia en su sentencia que durante el tiempo transcurrido desde el accidente hasta el juicio, el ecosistema se había restablecido, en gran parte, por causas naturales excluyendo así la necesidad de repoblar las especies. Como complemento de ello si se consideró resarcible el coste de los estudios científicos realizados para la elaboración del Plan.

La Sentencia de instancia fue apelada y el 24 de enero de 1992, la United States Court of Appeals for the Seventh Circuit dictó apelación del caso Amoco Cádiz. El Tribunal de apelación no examinó el no resarcimiento del daño ecológico, pues las partes afectadas habían decidido no presentar impugnación a esta cuestión. No obstante, sí se decidieron algunas cuestiones que tuvieron bastante relevancia para la determinación del daño resarcible en caso de graves incidentes que afectaran al ambiente. Así, la sentencia de apelación confirmó que el coste de los servicios prestados por los agentes públicos, civiles o militares, en las actividades de restablecimiento del ambiente debía ser imputado al responsable del incidente y aunque mantuvo el principio de que los servicios públicos son gratuitos ello tenía una excepción cuando una ley dispusiera lo contrario como era el caso del Amoco Cádiz ya que el artículo 16 de la Ley francesa n. ${ }^{\circ} 76-599$ del 7 de julio de 1976, preveía un caso específico el carácter oneroso de los servicios públicos en el que podía subsumirse la situación del accidente del Amoco Cádiz. Además el Tribunal completaba su razonamiento afirmando que era necesario tomar también en cuenta los "committed costs", pues los agentes públicos ejecutaban una multitud de funciones, de modo que su exclusiva o prevalente dedicación a una tarea determinada hacía más onerosa la ejecución de sus demás deberes ordinarios.

La sentencia de apelación rechazó la demanda promovida por algunos municipios del departamento de Cotes du Nord para reparar del daño a la reputación del lugar de veraneo. Según los demandantes, la cantidad que ellos reclamaban debió haberse añadido a lo ya pagado a los municipios y a quienes allí ejecutaban actividades en el sector del turismo. Para el resarcimiento de los daños de naturaleza económica los municipios argumentaban que era válido un criterio específico para evaluar el daño a su fama como lugar de veraneo. Según ese criterio había que tener en cuenta dos factores: primero, la disminución de goce de los turistas, obligados a pasar sus vacaciones en un lugar diferente de su destino preferido en Cotes du Nord y, segundo, el mayor tiempo necesario para llegar a los otros lugares. 
El Tribunal no consideró válido dicho criterio pues lo calificó de aproximado e hipotético y para ello argumentó que: en primer lugar, aunque se aceptara la existencia del daño, el resarcimiento correspondiente se debía a los turistas y no a los municipios; en segundo lugar, debido a que la pérdida de flujo de turistas en los municipios de Cotes du Nord suponía un provecho para los lugares de veraneo situados en otra parte, cabía aplicar el criterio jurisprudencial según el cual normalmente no se reconoce un derecho de resarcimiento si el hecho comporta una translación de los beneficios de un operador a otro y, en tercer lugar, no podía considerarse obvia la base misma del criterio evocado, es decir, que los turistas que no habían podido ir a Cotes du Nord, habrían viajado a otros lugares más lejanos.

\section{Hitos a destacar}

El accidente del Amoco Cádiz se produjo en 1978 y entonces el concepto de daño ecológico no existía hasta tal punto que en este caso, como hemos visto, por un lado, los afectados, particulares e instancias públicas, reclamaron costes de índole eminentemente económica y patrimonial, sin tener en cuenta el daño a los valores intrínsecos de los recursos naturales que se vieron afectados por el vertido; por otro lado, frente a la tímida demanda por la destrucción de especies marinas y la consiguiente pérdida de biomasa, el Tribunal consideró que nadie estaba legitimado para obtener el resarcimiento por la desaparición de una "res nullius" y fue totalmente rechazada.

\section{La explosión, el incendio y el hundimiento del pozo petrolífe- ro Ixtoc-1}

A. El accidente y los daños ambientales ocasionados.

En 1978, concretamente el 10 de diciembre, la empresa estatal mexicana Petróleos Mexicanos (PEMEX) inició la perforación del pozo Ixtoc-1 a 94 kilómetros al Noroeste de Ciudad del Carmen, en la Bahía de Campeche (México). Para ello se utilizó una semisumergible que fue contratada por PEMEX a la compañía PERMARGO. Apenas 5 meses después, el 2 de junio de 1979, a una profundidad de 3.615 metros el pozo empezó a desprender lodo de perforación; la situación se complicó cuando a 3.627 metros la circulación del lodo de perforación se perdió completamente y a pesar de los esfuerzos realizados por intentar recuperar la circulación, retirando el tubo perforador y cerrando el hueco con un obturador, nada pudo lograrse. Al día siguiente, realizando maniobras para taponar el pozo, la extrema alta presión (sobre $350 \mathrm{Kg} / \mathrm{cm}$ ) provocó que el lodo ascendiera hasta la plataforma, el pozo explotó y se incendió, destruyendo y 
hundiendo la plataforma. Como consecuencia, el gas y el petróleo se mezclaron con el agua cerca del lecho marino, con ello empezó uno de los mayores derrames de petróleo en la historia de la exploración petrolífera. Aunque el 24 de junio se logró apagar el incendio, nuevamente se manifestó flujo de petróleo y gas en la superficie del mar, siendo éste un dato congruente de que existía una importante rotura bajo el equipo preventivo de erupciones. De este modo, PEMEX decidió la perforación de los pozos de alivio Ixtoc-1A e Ixtoc-1B, gracias a los cuales se logró extinguir el 9 de marzo de 1980 la última llama del pozo Ixtoc-1. Finalmente, el 25 de marzo de 1980, tras haberse inyectado seis tapones de obturamiento, el pozo quedó definitivamente taponado y controlado ${ }^{41}$.

En cuanto a los daños ambientales que se ocasionaron por el accidente, lo primero a destacar es que la plataforma continental en el Golfo de México constituye un ecosistema muy favorable para diversas especies de peces demersales, camarones, moluscos, cangrejos y otros invertebrados que son la base de una importante actividad pesquera y comercial. Además en la parte occidental del Golfo existen dos grupos de barreras de coral que constituyen un hábitat fundamental, especialmente como zonas de cría, de especies comercialmente importantes. Hay también bosques de mangles a lo largo de toda la costa, desde la ciudad de Campeche al Norte de Celestun, utilizados como zonas de alimentación en determinadas partes del ciclo vital de algunas especies migratorias, como los camarones. Una característica más de esta zona es que el litoral está formado, principalmente, por playas de arena y barreras de islas que a menudo encierran extensas lagunas y estuarios de poca profundidad, pero abundantes en camarones y ostras y que constituyen un hábitat importante de varias aves acuáticas.

Por ser precisamente esta zona muy rica en recursos naturales se puede afirmar que el accidente del pozo Ixtoc-1 tuvo unas consecuencias ambientales catastróficas debidas, principalmente, al volumen de petróleo derramado en el mar, ya que aunque en un principio, se estimó que el derrame era aproximadamente de 4.500 toneladas métricas diarias. Sin embargo, a principios de agosto el pozo había perdido un total de 225.000 toneladas métricas, más petróleo del que jamás se había derramado en ningún accidente previo de perforación o incluso de transporte de petróleo. Cuando, finalmente, el 25 de marzo de 1980, se logró controlar el accidente, un total de 450.000 toneladas métricas del crudo se habían escapado ${ }^{42}$.

${ }^{41}$ Vid. BADENES CASINO, M. M. "IXtoc-1" en La práctica internacional en materia de responsabilidad por accidentes industriales catastróficos/coord. por JUSTE RUIZ, J. y SCOVAZZI, T. 2005, págs. 65-94.

${ }^{42}$ Sobre los datos de petróleo vertido ver el Programa de las Naciones Unidas para el Medio Ambiente 


\section{B. La determinación del daño}

Lo más llamativo de este suceso en relación al tratamiento del daño ambiental fue la evaluación del mismo. Para ello, se adoptó un Programa Coordinado de Estudios Ecológicos en la Sonda de Campeche, elaborado conjuntamente por la Secretaría de Marina y el Departamento de Pesca del Gobierno mexicano y por PEMEX, empresa estatal mexicana que inició la perforación. Dicho Programa comprendía diversas actividades de estudio y vigilancia tanto de las características físicas y químicas del agua del mar, como de muestras de plancton recogidas en diferentes profundidades marinas. Los resultados de los análisis realizados llevaron a realizar las siguientes conclusiones: En primer lugar, los niveles de concentración de hidrocarburos en el agua del mar no rebasaban, en la mayoría de las muestras, los parámetros considerados como normales; en segundo lugar se contrastó que se detectaron manchas de petróleo en la Sonda de Campeche que no tenían nada que ver con el accidente del Ixtoc-1, sino que provenían de afloraciones submarinas naturales; en tercer lugar el informe oficial aseguraba que, según los resultados de este Programa, la mayor parte del petróleo derramado fue degradado por la propia naturaleza y, finalmente, los estudios sobre el plancton, tanto animal como vegetal, revelaron que no habían tenido lugar alteraciones significativas entre las especies, y que no se habían encontrado aves marinas ni peces muertos flotando sobre la superficie del mar atribuibles al derrame de petróleo.

Como el derrame llegó a contaminar las aguas de la zona de pesca de doscientas millas de la costa texana de los Estados Unidos, se realizaron análisis por los laboratorios del Naime Science Institute de la Universidad de Texas, que demostraron que existía un alto grado de intemperización de las fracciones de hidrocarburos que componían el crudo derramado por el Ixtoc-1, lo que hacía que el petróleo que hubiera podido llegar a las playas fuera completamente inocuo a pesar de que otras investigaciones realizadas a lo largo de la costa de Texas demostraron que aproximadamente unas 4000 toneladas métricas de petróleo se depositaron en dicha zona ${ }^{43}$.

(PNUMA) que se realizó a petición del Gobierno de México. Asimismo, PEMEX contrató a CIFSA, una empresa consultora mexicana para realizar estudios sobre el impacto ambiental del derrame y lo mismo hizo un equipo investigado; SOTO et al., Study of the Penaeid Shrimp population in relation to petroleum hydrocarbons in Campeche Bank, en VÁZQUEZ BOTELLO y VILLANUEVA, Review of the Health of the Oceans. Mexican Region of the Gulf of Mexico, México, Centro de Ciencias del Mar y Limnología, UNAM, México, 1987.

${ }^{43}$ Vid. Ixtoc-l Oil Blowout, Proceedings of a Symposium on Preliminary results from the September 1979 Researcher/ Pierce Ixtoc-l Cruise, Key Biscayne, Florida, june 9-10 1980, p. 36. 
Junto a estos resultados que podemos considerar oficiales, se realizaron otros estudios biológicos por científicos de ámbito universitario que pusieron de manifiesto una realidad diferente. Así el estudio realizado por dos profesores suecos, los doctores Lindén y Jernelöv, en el que pusieron de manifiesto que especies comercialmente importantes, como el camarón fueron afectadas por la toxicidad química del petróleo ${ }^{44}$. De hecho las huevas de esta especie en la Bahía de Campeche podrían haber sido particularmente afectadas, ya que suelen mostrar gran sensibilidad frente a los hidrocarburos. Debido al cambio de las corrientes y los vientos en otoño de 1979, el derrame de petróleo se movió hacia el Sur y el Sudeste, aumentando las amenazas a las huevas y larvas de camarón, abundantes en esa zona, por lo que posiblemente también afectó a los camarones juveniles y adultos. Del mismo modo, pusieron de manifiesto que, en la mayor parte de los casos, cuando se produce un derrame de petróleo los efectos que se produce sobre el ecosistema son de carácter metabólico y dependen del tiempo en que dichos organismos estén expuestos al contaminante. Si además se tenía en cuenta que el petróleo tenía alrededor de 500 componentes que de alguna manera podían afectar, a corto, medio y largo plazo, a los organismos marinos, no podía negarse que el accidente del pozo Ixtoc-1 sí que supuso un efecto negativo e importante sobre el ecosistema marino de la zona afectada.

\section{La mitigación del daño y los pronunciamientos jurisdiccionales}

En cuanto a la mitigación del daño, la primera medida que se adoptó por las empresas que explotaban la plataforma fue la contención del derrame, que se llevó a cabo anclando una especie de barreras en unos puntos fijos pegados a unas barcas auxiliares que encerraban el petróleo utilizando picotijeras y aparatos absorbentes para recuperar el petróleo. Posteriormente, estas empresas optaron por contratar a empresas extranjeras especializadas en las actividades de detención de derrames marinos ${ }^{45}$. A pesar de ello, las fuertes corrientes que cruzaban los entrantes impidieron que dichas barreras fueran efectivas pues, o bien las rompían, o bien las empujaba debajo o encima del agua, por ello se tuvo que realizar un intenso trabajo de dispersión química desde aviones y barcos para evitar que los posibles daños ambientales a las costas fueran peores.

Además de estas medidas de contención se realizaron actividades de recupe-

\footnotetext{
${ }^{44}$ Vid. JERNELÓV y LINDEN, "Ixtoc-1: A Case Study of the World's Largest Oil Spill”, op. cit., p. 306.

45 Vid. DÍAZ, L.M. "Responsabilidad del Estado y contaminación. Aspectos jurídicos”, México, Porrua, 1982, p. 139
} 
ración en las zonas contaminadas, así por ejemplo se procedió a la limpieza de playas, laguas y estuarios que se repitieron hasta en 4 ocasiones. Uno de los métodos de limpieza consistía en cubrir la arena contaminada con arena limpia. De igual modo una de las tareas de recuperación con mejores resultados que se realizaron consistió en la salvaguarda de las cría de tortugas loras que se trasladaron mar adentro desde la playa de Rancho Nuevo a un lugar adecuado señalado por biólogos para evitar que las crías quedaran atrapadas por fragmentos de asfalto.

Por lo que se refiere a los pronunciamientos jurisdiccionales, el primer dato que hay que tener en cuenta es que tanto la jurisprudencia como la doctrina internacional aceptaban de manera unánime que los actos de los órganos estatales se atribuyen al Estado en cuanto que sujeto de Derecho Internacional. Es por ello que, siendo PEMEX un organismo público descentralizado del Gobierno Mexicano, cualquier responsabilidad que pudiera imputársele involucraría la responsabilidad del Estado de México. En consecuencia y según la legislación mexicana, ${ }^{46}$ correspondía a la Nación Mexicana el dominio directo de los carburos de hidrógeno que se encontraran en territorio nacional incluida la plataforma continental, y por tanto, a la Nación le correspondía la exploración y explotación del petróleo así como las demás actividades que abarcaran la industria petrolífera. Es por ello que el Estado estaba ejerciendo un derecho soberano y fue exonerado de responsabilidad internacional ${ }^{47}$.

Aún así, PEMEX fue demandada ante el Juez del Distrito de Texas por los daños ocasionados en el Estado de Texas. Las demandas se agruparon en tres tipos: a) las interpuestas por grupos de pescadores de las costas de Texas; b) las interpuestas por terratenientes y empresarios de negocios e inmuebles ubicados en la playas de Texas y c) las autoridades recaudadoras de los condados de Padre South Island y Willacy ${ }^{48}$. A todas estas demandas PEMEX presentó la misma excepción consistente en la falta de jurisdicción del Tribunal estadou-

\footnotetext{
${ }^{46}$ Ley Reglamentaria del artículo 27 de la Constitución del Estado de México; la Ley Orgánica de Petróleos Mexicanos.

${ }^{47}$ En este caso concurre el dato de que México no había firmado el Convenio de Londres de 1977 sobre responsabilidad civil por daños por contaminación de hidrocarburos derivada de la exploración y explotación de recursos minerales del subsuelo marino, ni el Convenio de Bruselas de 29 de noviembre de 1969 ni el Convenio Internacional de constitución de un fondo internacional de indemnización por daños causados por la contaminación de hidrocarburos de 1971.

${ }^{48}$ Vid. LÓPEZ, D. A. "Antecedentes y comentarios del accidente del pozo Ixtoc-1 y de los juicios derivados del mismo en los Estados Unidos de América en contra de Petróleos Mexicanos", Pemex Lex, enero-febrero 1991.
} 
nidense al ser aquel un órgano estatal mexicano y realizar por tanto actos de carácter soberano. Tras examinar el juez norteamericano las cuestiones relativas a la inmunidad soberana y a las actividades soberanas con respecto a los recursos naturales del Estado, en su sentencia concluyó que PEMEX estaba ejecutando un plan nacional formulado a los más altos niveles del Gobierno Mexicano en el ejercicio de las actividades de explotación de México sobre sus recursos naturales y que por tanto no se podía negar la inmunidad del Estado extranjero por la aplicación de su política económica doméstica. Es por ello que se declararon improcedentes todas las demandas en contra de PEMEX ${ }^{49}$ y por ello no se entró a analizar lo relativo al daño y su valoración.

\section{Hitos a destacar}

La primera consecuencia que queremos resaltar en cuanto al tratamiento de los daños ambientales en este asunto es que tanto el Estado Mexicano como PEMEX trataron de disminuir y eliminar los efectos del daño ambiental y el daño ambiental mismo, el tratamiento que el daño ambiental tuvo en este caso dista de estar claro pues hemos mostrado que existieron dos posiciones encontradas. Por un lado, los informes que podemos considerar oficiales cuyas conclusiones afirmaron que prácticamente no existieron daños ambientales causados por el accidente; y por otro lado, los informe y estudios de científicos universitarios independientes que pusieron en cuestión tales conclusiones y evidenciaron el impacto negativo del derrame sobre el medio marino.

En este asunto tampoco se puede valorar el pronunciamiento judicial sobre el daño ambiental puesto que no existió ya que aunque se plantearon demandas debido a los daños en la costa del Estado de Texas contra PEMEX, el Tribunal estadounidense aceptó la excepción presentada por PEMEX de inmunidad del estado y de realización de actos soberanos y por tanto no pudo entrar en el fondo de las cuestiones planteadas.

Aún así es menester afirmar que el desastre del Ixtoc-1 supuso un paso positivo en el camino de la protección del medio marino, pues pocos meses después del accidente, los respectivos presidentes de los Estados implicados decidieron negociar acuerdos para prevenir daños futuros al medio ambiente. Como consecuencia de estas negociaciones se adoptó finalmente el Acuerdo de

\footnotetext{
49 Sobre la inmunidad del Estado de México en este asunto Vid. GÓMEZ ROBLEDO VERDUZCO, "A Propósito del Ixtoc-1", Anuario Jurídico, 1983, pp. 411 y ss.; ibíd., Temas selectos de Derecho Internacional, 1.” ed., México, UNAM, Instituto de Investigaciones Jurídicas, 1986, pp. 147 y ss.
} 
Cooperación entre México y Estados Unidos sobre la Contaminación del Medio Marino por Derrames de Hidrocarburos y otras Sustancias Nocivas que entró en vigor el 30 de marzo de $1981^{50}$. Este acuerdo tenía la finalidad de desarrollar medidas que permitieran tratar incidentes contaminantes y garantizar una respuesta adecuada que pudiera garantizar una respuesta adecuada en cada caso que pudiera afectar de manera significativa al medio marino de ambos Estados tanto en los supuestos de derrames efectivos como en caso de amenaza de derrames inminentes.

El ámbito de aplicación del convenio se extendía al área de mar, incluida la costa adyacente, que se encuentra del lado de su frontera marítima establecida por la otra Parte o con otros Estados, dentro de las doscientas millas marinas medidas desde la líneas de base desde las que se miden sus respectivos mares territoriales, por tanto, quedaba fuera de su ámbito de aplicación el supuesto de que como consecuencia de una explotación de hidrocarburos en el interior de las zonas marítimas sometidas a su soberanía o jurisdicción nacional se produjeran daños en el alta mar, fuera de las doscientas millas marinas.

Las medidas a las que se obligaron cada uno de las Estado fueron las siguientes: a) Cada Estado se comprometía a detectar la existencia o la posibilidad inminente de que ocurrieran incidentes contaminantes y a eliminar los posibles efectos adversos que pudieran conllevar a través del diseño y desarrollo de sistemas operativos nacionales aplicables dentro de sus respectivas áreas; b) ambos Estados se comprometían a cooperar para prevenir y combatir cualquier daño a través del intercambio de informaciones, pare ello se diseñaron la creación de unas Autoridades coordinadoras del Plan que eran las únicas competentes para actuar en su respectivo Estado ${ }^{51}$.

Aunque debemos concluir con una valoración positiva del Acuerdo, puesto que fue el instrumento que puso de manifiesto la voluntad de ambos Estados de dar una respuesta adecuada a futuros derrames que evitaran en lo posible los daños ambientales, hoy se pone en cuestión tras el reciente incidente del 20 de Abril de 2010 en el que la plataforma petrolífera Deepwater Horizon, pro-

\footnotetext{
${ }^{50}$ México D.F., 24 de Julio de 1980.

${ }^{51}$ Sobre las negociaciones y el desarrollo en la ejecución de este acuerdo vid. VÁZQUEZ BOTELLO, A. "Golfo de México: contaminación e impacto ambiental: diagnóstico y tendencias", Edición. Univ. A. de Campeche, UNAM, Instituto Nacional de Ecología, 2005.
} 
piedad de British Petroleum, Transocean y Halliburton, ha explotado y se ha hundido en el Golfo de México, provocando un derrame de petróleo que recuerda el incidente de Ixtoc- ${ }^{52}$.

\section{El complejo tratamiento de los daños ambientales en los acci- dentes de los petroleros Patmos y Haven}

\section{A. Los accidentes y sus respectivos contextos}

El 21 de marzo de 1985 el petrolero griego Patmos colisionó con el buque español Castillo de Montearagón, mientras navegaba por el estrecho de Mesina. Como consecuencia de la colisión, se derramó de los tanques del Patmos una cantidad indeterminada de petróleo, parte de la cual alcanzó las costas de Sicilia.

El 11 de abril de 1991, el petrolero Haven, con pabellón chipriota, se incendió mar adentro frente al puerto de Génova. El buque sufrió una serie de explosiones que rompieron el casco en tres partes. Como consecuencia del accidente se estimó que 10.000 toneladas de hidrocarburos se derramaron al mar, contaminando las costas de Luguria y Francia.

En estos asuntos es importante situarnos en el contexto normativo centrándonos en el Convenio de Bruselas de 1969 sobre responsabilidad civil nacida de daños debidos a contaminación por hidrocarburos y el Convenio de Bruselas de 1971 sobre la constitución de un Fondo internacional de indemnización de daños debidos a contaminación por hidrocarburos, que se han venido a llamar el núcleo del "Sistema de Bruselas" y que se completa con la firma de una serie de protocoles posteriores concretamente el Protocolo de 1976 y el Protocolo de 1992. ${ }^{53}$. Señalemos que Italia, principal Estado dañado por los accidentes del Patmos y Haven, era parte en los Convenios mencionados y en el protocolo de 1976, pero no suscribió el protocolo de 1992 como veremos a renglón seguido.

\footnotetext{
${ }^{52}$ Este accidente no es objeto de análisis en este estudio porque por su carácter reciente sobre el mismo no hay aún pronunciamientos jurisprudenciales.

${ }^{53}$ En el primero se modificaron las unidades de cuenta previstas por los convenios y en el segundo, se elevaron las sumas que podían percibir los sujetos damnificados a título de indemnización e introdujo una definición diferente de daño por contaminación. Respecto al funcionamiento del mecanismo de reparación del "Sistema de Bruselas" Vid. MERIALDI, A. "Patmos y Havem en La práctica internacional en materia de responsabilidad por accidentes industriales catastróficos, Coord. SCOVAZZI, T. y JUSTE RUIZ, J. Tirant lo Blanc, Valencia, 2005, págs. 116-118.
} 
B. La posición del Estado Italiano respecto al daño ambiental y los problemas de aplicación del "Sistema de Bruselas"

\section{a) El concepto de daño por contaminación en el Sistema de Bruselas.}

La noción de daños por contaminación lo tenemos expresado en el artículo I del Convenio de Bruselas de 1969. Éste contiene una amplia definición de los daños al considerarlos como las pérdidas o daños causados fuera del barco que transporte los hidrocarburos por la contaminación resultante de derrames o descargas procedentes del barco, donde quiera que ocurran tales derrames o descargas, e incluyendo el costo de las medidas preventivas y las perdidas o daños causados por tales medidas preventivas. Por tanto podemos afirmar claramente que la noción de daños por contaminación posee un matiz de naturaleza económica al ampliar el concepto de daño a los costes de las medidas de remoción del petróleo, los costes de determinadas medidas preventivas y los daños de carácter patrimonial debidos a la contaminación (tanto por lo que se refiere al daño emergente como al lucro cesante). Ahora bien, fuera de ese concepto quedan los daños a la salud humana y los daños al medio ambiente por lo que, es claro que esta normativa no proporciona indicaciones acerca de los criterios para su valoración. Esta falta de alusión a los daños medio ambientales se debe a que en el momento de la elaboración del Convenio, ese tipo de perjuicios no se tomaban todavía en consideración en la práctica jurídica internacional relativa a la reparación de los daños ocasionados por la contaminación por hidrocarburos. Fue precisamente en 1979 en el accidente del petrolero soviético Antonio Gramsci en el Mar Báltico en el que una autoridad pública, la autoridad soviética, presentó una demanda de reparación por los daños al medio ambiente. La demanda consistió en la reclamación de una cantidad económica por los daños ambientales que se calculó tomando como base un procedimiento especial previsto por la legislación soviética, llamado Metodika. Según este procedimiento los daños al medio ambiente debían valorarse multiplicando la suma de 2 rublos por cada metro cúbico de agua contaminada, y el volumen de agua contaminada se calculaba de forma hipotética tomando como base la cantidad de hidrocarburos derramados en el mar. Este método no fue aceptado por los órganos del Fondo internacional de indemnización de daños debidos a contaminación por hidrocarburos y como consecuencia de ello en 1980 su Asamblea adoptó por unanimidad la Resolución núm. 3, que establecía que los daños ambientales podían ser indemnizados sólo cuando los damnificados hubieran sufrido un perjuicio económicamente cuantificable. La motivación de la Asamblea en la aprobación de esta resolución no era más que el intento de evitar la proliferación de reclamaciones de indemnización por daños al medio ambiente de naturaleza instru- 
mental. Este temor quedó reflejado en la redacción dada al párrafo 6 del art. I del Protocolo de 1992 al Convenio de Bruselas de 1969 que contenía la nueva definición de los daños de contaminación en la que es novedoso que se incluya una referencia expresa al daño al medio ambiente, pero en la que se establecieron límites rigurosos para su aceptación. Según este nuevo texto eran daños ocasionados por contaminación las pérdidas o daños causados fuera del buque por la impurificación resultante de las fugas o descargas de hidrocarburos procedentes de ese buque, dondequiera que se produzcan tales fugas o descargas, si bien la indemnización por deterioro del medio, aparte de la pérdida de beneficios resultante de dicho deterioro, está limitada al costo de las medidas razonables de restauración efectivamente tomadas o que vayan a tomarse.

b) Las objeciones del Estado Italiano al concepto de daño por contaminación en el sistema de Bruselas. Las previsiones del Derecho interno italiano.

La generalidad de los Estados han seguido el criterio de la Resolución núm. 3 de 1980, pero el Estado italiano, aunque participó en su aprobación, desde el asunto del petrolero Patmos, que estamos analizando, se ha opuesto a la solución del problema de la liquidación de los daños por contaminación por referencia a los costes de la recuperación del medio ambiente. Como consecuencia de ello Italia no firmó los Protocolos de 1992 al Convenio de Bruselas de 1969 y al Convenio de Bruselas de 1971, exponiendo su posición con carácter público y general en un documento presentado al Comité Jurídico de la OMI (LEG) tras la Conferencia celebrada en 1992 para la adopción de los Protocolos. En este documento se solicitaba la revisión del sistema de determinación de los daños para permitir a las víctimas obtener una indemnización establecida según la equidad, tomando en consideración tres factores guías: la cantidad de sustancias derramadas, su naturaleza e impacto químico-físico sobre el hombre, la flora y la fauna y, finalmente, las características naturales y económicas del área afectada por la contaminación, todo ello para tener en cuenta las peculiares condiciones del medio ambiente en el Mediterráneo y la importancia que tiene el turismo para la economía de los Estados ribereños.

Como consecuencia de la no adhesión a los Protocolos de 1992, los casos de daños al medio ambiente continuaban sometidos en Italia a las reglas previstas por los textos originarios de los Convenios de Bruselas de 1969 y 1971, los cuales, como no incluían disposiciones específicas relativas a los daños al medio ambiente, hicieron necesario que tuviera que acudirse a las normas de derecho interno italiano. Estas normas fueron: 
- La Ley 979 de 31 de diciembre de 1982 sobre disposiciones para la defensa del mar, en cuyo artículo 21 se asignaba al capitán y al propietario del buque, solidariamente, la obligación de reparar los daños causados a los recursos naturales cuando había habido una violación de las normas sobre los vertidos en el mar establecidas por la Ley.

- La Ley 349 de 8 de julio de 1986, que creó el Ministerio de Medio Ambiente y estableció la normativa general aplicable a los daños ambientales. En cuanto a la valoración de los daños, el artículo 18 de la Ley ${ }^{54}$ preveía que en el caso en que fuera imposible su determinación precisa, éstos podían ser calculados tomando como base la equidad, teniendo en cuenta los siguientes tres factores: los costes de la recuperación del medio ambiente; la gravedad de la culpa del sujeto autor de los daños; y los beneficios obtenidos por el sujeto autor de los daños.

C. Los pronunciamientos jurisdiccionales que resolvieron la cuestión de la reparación de los daños al Medio Ambiente en los asuntos Patmos y Haven

a) La reparación de los daños en el asunto Patmos.

En este asunto el Estado Italiano presentó una demanda de reparación por daños al medio ambiente, cuyo montante se elevaba a 5 mil millones de liras. $\mathrm{Al}$ ser formulada la reclamación en términos totalmente abstractos fue desestimada por el Tribunal de Mesina ${ }^{55}$. En los fundamentos jurídicos de la sentencia se decía que la demanda debía ser desestimada por resultar incompatible con lo dispuesto en la Resolución núm. 3, ya que el Gobierno italiano no había justificado el modo de determinación de la suma reclamada además de que no había constancia, en la demanda, de que la parte demandante hubiera tenido que hacer frente a ninguna perdida económica derivada de la limpieza del litoral o actuaciones similares. Frente a esta Sentencia el Gobierno Italia-

\footnotetext{
${ }^{54}$ El artículo también prevé que el juez tiene la obligación de ordenar la restauración de los lugares a expensas del autor de los daños en todos los casos en que esta restauración sea posible. Y en cuanto a la titularidad del derecho a la reparación, le corresponde exclusivamente al Estado, mientras que las entidades territoriales locales poseen únicamente la legitimación judicial emprendiendo acciones para la reparación de los daños, pero sin recibir la indemnización. Tampoco se prevé el derecho a una reparación para las asociaciones ecologistas, que tienen sólo el derecho de carácter meramente procesal de intervenir en el juicio.

55 Vid la Sentencia de 30 de julio de 1986, del Tribunal de Mesina, consultar texto en Il Diritto Marittimo, 1986, pp. 996-1015.
} 
no, presentó un recurso y el Tribunal de Apelación de Mesina asumió una posición totalmente diferente, estimando la demanda del Gobierno italiano e ignorando por completo la Resolución núm. $3^{56}$. La Sentencia del Tribunal de apelación siguió en su motivación la doctrina de la Sentencia del Tribunal Constitucional italiano núm. 641 de 30 de diciembre de 1987, en la que se afirmaba que los daños al medio ambiente debían ser reparados con independencia de la realización de actividades para su rehabilitación. De acuerdo con ello, los daños al medio ambiente se concretaban en los perjuicios económicos equivalentes a la perdida de los usos que la colectividad pudiera hacer del medio ambiente, por tanto había de tener en cuenta los usos de alimentación, turismo, salud e investigación científica, entre otros.

Ahora bien, el reconocimiento del deber de reparar los daños, con independencia de los costes de rehabilitación del medio ambiente, como se ha dicho, añadió una complejidad al proceso judicial, cual era la determinación de la pérdida de valor del medio ambiente como consecuencia del accidente. Para solucionar esta complejidad el Tribunal adoptó la siguiente solución: los daños al medio ambiente, por cuanto se refieren a un bien que no es susceptible de valoración económica, debían determinarse según la equidad, como se ha explicado con anterioridad, para ello se tomó como base un peritaje técnico sobre la existencia y entidad de los daños. De esta forma, el Tribunal reenvió la determinación del quantum a una futura decisión que debería ser adoptada tomando como base los resultados de un peritaje técnico. En su aplicación concreta esta solución dio lugar a una serie doble de problemas: por un lado, el tiempo empleado resultó muy largo, pues los peritos presentaron su informe final más de tres años después de haber sido nombrados, debido a las dificultades encontradas para valorar, varios años después del accidente, los efectos ambientales de la contaminación ${ }^{57}$; por otro lado, el Tribunal de Apelación rechazó el método de liquidación de los daños utilizado por los peritos. Este método consistió en fijar el montante de esos daños calculando la cantidad de pescado que, presumiblemente, no había sido capturado como consecuencia de la contaminación y multiplicándola por su precio al por mayor. A este respecto el Tribunal considero que los peritos se habían equivocado al querer atribuir al bien jurídico medio ambiente un valor de mercado que no tenía relación con

\footnotetext{
56 Vid la Sentencia de 30 de marzo de 1989, núm. 142, del Tribunal de Apelación de Mesina, consultar texto en Rivista Giuridica dell'Ambiente, 1990, pp. 527-534, con nota de MEDUGNO, pp. 534-538.

${ }^{57}$ Por ello, la decisión final acerca del quantum de la indemnización sólo pudo ser adoptada por el Tribunal de Apelación a finales de 1993. Vid la Sentencia 24 de diciembre de 1993, del Tribunal de Mesina en Rivista Giuridica dell'Ambiente, 1994, pp. 683-694, con nota de RONCELLI.
} 
el carácter de este bien. Finalmente, el Tribunal en su decisión sobre la fijación concreta de los daños tomó en cuenta también el valor de mercado del pescado, aunque fijándolo en un precio más bajo que el indicado por los peritos. Precisamente por ello es cuestionable la coherencia del Tribunal respecto al principio de equidad evocado. Algunos autores estiman que la Sentencia ha de ser interpretada correctamente y que por ello la clave está en tener en cuenta que el valor de mercado de los recursos naturales perdidos (o que no han llegado a existir) no puede ser considerado como un factor capaz de determinar por sí sólo el valor del medio ambiente y de los daños resultantes, sin embargo, dicho valor de mercado constituye una circunstancia que el juez puede tomar en consideración, junto a otros factores, en el momento de realizar la liquidación de los daños según la equidad ${ }^{58}$.

\section{b) La reparación de los daños en el asunto Haven.}

En el asunto del Haven, Italia presentó nuevamente una demanda de reparación por daños al medio ambiente. La reclamación tenía en este caso una estructura más compleja que en el asunto del Patmos, ya que comprendía los costes de las medidas de rehabilitación del medio ambiente, los daños por la disminución de valor de los recursos naturales afectados por el accidente y los daños no cuantificables, cuya determinación se dejaba a la decisión del Tribunal según la equidad. La Sentencia del Tribunal de Génova, que fue el competente para conocer del asunto se centró principalmente en la exigencia de la recuperación del medio ambiente ${ }^{59}$. El Tribunal observó que el restablecimiento del estado anterior al hecho perjudicial en los lugares afectados constituía el fin último del sistema de reparación aplicable en virtud del artículo 18 de la Ley 349 de 1986. El Tribunal afirmaba que si el objetivo del restablecimiento pudiese conseguirse de forma plena, los responsables deberían responder sólo en los límites de los costes necesarios para la rehabilitación íntegra. Según el Tribunal, sólo en el caso en que el restablecimiento completo fuera imposible o excesivamente oneroso era necesario liquidar de forma equitativa el perjuicio residual al medio ambiente. Como el peritaje técnico solicitado por el Tribunal demostraba en efecto que una apreciable cantidad de crudo continuaba cubriendo el fondo del mar en las zonas más profundas del área afectada por el accidente se cumplía esta condición. Por ello para el Tribunal el coste de las

\footnotetext{
58 Vid. MERIALDI, A. "Patmos y Havem en en La práctica internacional en materia de responsabilidad por accidentes industriales catastróficos, Coord. SCOVAZZI, T. y JUSTE RUIZ, J. Tirant lo Blanc, Valencia, 2005, cit. Pág. 133.

${ }^{59}$ Vid la Sentencia de 5 de abril de 1996, del Tribunal de Génova en II Diritto Marittimo, pp. 500-520.
} 
operaciones de restablecimiento constituía el parámetro fundamental de referencia para la evaluación equitativa del daño residual al ambiente, con el fin de concretar de forma objetiva la medida del mismo.

En este asunto, distintas entidades territoriales como la Región, la Provincia y distintos Ayuntamientos afectados por el derrame de crudo se personaron en el proceso judicial reclamando la reparación por pérdida de la imagen turística. Esta reclamación fue completamente desestimada por el Juez, primero por la falta de legitimación activa de las entidades locales que invocaban ésos daños ya que la legitimación correspondía exclusivamente a aquéllos que, como los operadores turísticos, hubieran sufrido daños económicos en razón de la disminución de la afluencia de turistas en el área afectada por el accidente. El Juez sólo preveía un supuesto en el que procediera la reparación de los daños por pérdida de la imagen turística a favor de las entidades locales: los daños serían reparables en los casos en que la contaminación invalidara la eficacia de las actividades de promoción del turismo emprendidas por las entidades locales o cuando éstas hubieran tenido que efectuar inversiones específicas del mismo tipo como consecuencia de la contaminación, cuestión esta que no fue planteada en ninguna de las demandas que se centraron en conectar los daños por pérdida de la imagen turística con la disminución de las posibilidades de aprovechamiento de los recursos naturales, asemejándolos en algunos aspectos a los daños al medio ambiente.

\section{Hitos a destacar}

Hemos visto como hasta los asuntos Patmos y Haven el método de valoración de los daños al Medio Ambiente había evolucionado lentamente, desde no aplicar ningún método por no contemplarse en concepto de daño ecológico, como en el asunto Amoco Cádiz, hasta aplicarse un método de valoración en función de los costes de restablecimiento de las condiciones del medio ambiente, como en el asunto Patmos y Haven. Esta última tendencia posé sus ventajas y sus desventajas: entre sus ventajas, ofrece una solución sencilla y garantiza la seguridad jurídica al considerar los daños al medio ambiente como una categoría de daños económicos que pueden liquidarse con bastante facilidad, concretándose en los gastos a los que el damnificado ha tenido que hacer frente para la ejecución de medidas razonables de rehabilitación del medio ambiente; entre sus desventajas, hay que destacar que el método de valoración de los daños no toma en consideración de forma plena los daños soportados por la colectividad que ha sido víctima de la contaminación, y como consecuencia de ello no sirve para indemnizar a dicha colectividad de la pérdida soportada en el caso en que el restablecimiento sea imposible, ni ofrece reparación alguna a la disminución de las 
posibilidades de aprovechamiento de los recursos naturales durante el tiempo comprendido entre el momento del accidente y la rehabilitación. Por esta razón y por la creciente atención que la opinión pública internacional dirige hacia el medio ambiente, se hace necesario tener en cuenta otros métodos de valoración y por ello el método seguido en los Asuntos Patmos y Haven, en los que se fijaron los daños al medio ambiente sobre la base de la equidad a partir de peritajes técnicos realizados en el área del accidente y orientados a averiguar la entidad del impacto sobre el medio ambiente, consideramos que son un hito importante a tener en cuenta en la introducción de correcciones y mejoras de los mecanismos de valoración previstos por el sistema de Bruselas.

\section{La consideración de los daños al medio Ambiente en el caso de Petrolero Exxon Valdez}

\section{A. El accidente y las consecuencias ambientales}

En la noche del 24 de marzo de 1989, el superpetrolero de 30.000 toneladas Exxon Valdez, navegando a una velocidad de 12 nudos, chocó con el arrecife Bligh Reef, en Prince William Sound (Alaska). El accidente tuvo lugar a 28 millas de la terminal Valdez del oleoducto trans-Alaska, en la que el buque Exxon Valdez había llenado sus tanques cargando más de 170.000 toneladas de crudo $^{60}$. Se descargaron al mar once millones de galones de hidrocarburos. Cinco meses después del accidente la descarga de hidrocarburos afectaba a unas 10.000 millas cuadradas de agua en Prince William Sound y en el Golfo de Alaska. Esta descarga afectó y dañó a áreas extremadamente ricas en recursos naturales: se recogieron unas 36.000 aves muertas, aunque los expertos consideraron que murieron más de 22 orcas, varios billones de huevos de salmones y de arenques; 100.000 aves, incluyendo unas 150 águilas calvas, declaradas especie protegida internacionalmente por estar en grave peligro de extinción; como mínimo, 1.000 nutrias de mar desaparecieron, a pesar de un programa de rescate y rehabilitación que costó 8 millones de dólares; el Patrimonio arqueológico resultó dañado al igual que importantes zonas de recreo: bosques nacionales, refugios nacionales de vida salvaje, monumentos nacionales, parques nacionales y estatales y múltiples zonas de recreo privadas ${ }^{61}$.

${ }^{60}$ Para conocer más detalles sobre la forma y los motivos por los que se produjo el accidente Vid. BOU FRANCH, V. Capítulo VIII: Exxon Valdez en La práctica internacional en materia de responsabilidad por accidentes industriales catastróficos, Coord. SCOVAZZI, T. y JUSTE RUIZ, J. Tirant lo Blanc, Valencia, 2005, págs. 192-262.

${ }^{61}$ La primera cuantificación de los daños causados a los recursos naturales en el accidente del Exxon 
B. El procedimiento seguido en el caso para la determinación de los daños ambientales

En el asunto del buque superpetrolero Exxon Valdez se abordó el problema del daño ambiental, con una profundidad desconocida hasta el momento. Las primeras medidas que se adoptaron fueron distintas comparecencias ante el Comité del Senado estadounidense sobre Comercio, Ciencia y Transporte para determinar las causas, efectos del accidente y las acciones públicas que se iban a llevar a cabo ${ }^{62}$. A continuación se inició la reclamación de los daños, siguiendo lo previsto en la Federal Clean Water Act y en la Comprehensive Environmental Response, Compensation, an Libiality Act, para ello era necesario por un lado, crear el Exxon Valdez Oil Spill Trustee Council, que consistía en un organismo público formados por funcionarios del Departamento de Agricultura, Comercio, e Interior y de la NOAA (National Oceanic and Atmospheric Administration) Gobierno Federal de los Estados Unidos y de funcionarios del Gobierno del Estado de Alaska; y por otro lado, elaborar el State /Federal Natural Resource Damage Assessment Plan for the Exxon Valdez Oil Spill que consistía en un Plan que describía los trabajos previos para valorar los daños que sufrieron los recursos naturales como consecuencia de la descarga.

La valoración de los daños se centraba en identificar y documentar los recursos que habían resultado afectados adversamente por los hidrocarburos, así como en medir los efectos adversos en cada recurso. Por otro lado el Plan contenía la estrategia a seguir para restaurar los recursos naturales y también la determinación de los daños, incorporando para esto último 73 estudios separados, que perseguían aportar una base para la valoración de los daños a los recursos naturales, mediante la determinación de la naturaleza y alcance de los perjuicios, pérdidas y destrucción de recursos. El primer Plan se aprobó en 1989 y tras una serie de modificaciones y actualizaciones ${ }^{63}$ se publicó en 1994 la versión definitiva del Restoration Plan, en cuya elaboración participaron más

\footnotetext{
Valdez se puede consultar en "Summary of effects of the Exxon Valdez Oil Spill on Natural Resources and Archaeological Resources", publicado en Oil Spill Intelligence Report, 24/13, p. 3.11 april 1991.

62 Vid. "Exxon Valdez Oil Spill and Its Environmental and Maritime Implications", Hearings Before the Senate Committee on Commerce, Science and Transport, 101st Cong., 1st Sess., pt. 1 (1989); "Cleanup, Containment, and Impact of the Exxon Valdez Oil Spill and Oil Spill Prevention and Maritime Regulations", $\mathrm{He}^{-}$ arings Before the Natural Ocean Policy Study and the Subcommittee on Merchant Marine of the Senate Committee on Commerce, Science and Transport, 101st Cong., 1st Sess., pt. 2, (1989).

${ }^{63}$ El Plan se publicó en agosto de 1989. Tras esta publicación, el Trustee Council publicó otra vez una versión modificada y actualizada del Plan, titulada The 1991 State/Federal Natural Resource Damage Assessment and Restoration Plan for the ExxonValdez Oil Spill, este plan también fue objeto de trabajos de perfeccionando en los años siguientes, que llevaron al texto final de 1994.
} 
de 2.000 personas, y en el que se contenía la Lista de servicios y de recursos dañados. Además, debe tenerse en cuenta que, tras la publicación del Plan de restauración, el Trustee Council realizó una importantísima labor de seguimiento tanto de la valoración de los recursos dañados como de su estado de recuperación y grado de cumplimiento del Plan ${ }^{64}$. Es importante mencionar que la Lista de servicios y de recursos dañados tenía tres objetivos fundamentales: el primero, representar los daños causados por la descarga, así como los esfuerzos de limpieza y las ayudas recibidas del Trustee Council y servir para el seguimiento público del grado de recuperación de los recursos y de los servicios de las zonas afectadas; el segundo, facilitar la identificación de las prioridades anuales en la aplicación del Plan de restauración de 1994; y el tercero, ayudar a la comprensión global del ecosistema de las zonas afectadas, así como de las funciones y servicios que provee.

En cuanto a la valoración de los daños, en el momento el accidente del Exxon Valdez, la normativa norteamericana aplicable al asunto era la Clean $\mathrm{Wa}^{-}$ ter Act y la Comprehensive Environmental Response, Compensation, and Liability Act. En la primera de ellas se establecía que los representantes federales o estatales estaban autorizados para actuar como Ministerio público para recuperar los costes de reemplazar o restaurar los recursos dañados o destruidos y que las cantidades que se obtuvieran debían ser utilizadas para restaurar, rehabilitar o adquirir el equivalente de los recursos naturales dañados o destruidos. Por su parte, la segunda ley mencionada, preveía que los representantes gubernamentales estatales y federales actuaban como administradores legales para proteger los intereses públicos en los recursos naturales, valorando los daños causados y presentando reclamaciones judiciales para recuperar los daños de las partes presuntamente responsables, y al igual que en la Ley anterior las sumas recuperadas a través de tales reclamaciones se utilizarían exclusivamente para restaurar, reemplazar o adquirir el equivalente de los recursos naturales dañados.

Ahora bien, la aplicación de estas leyes implicaban un problema, cual era que los perjuicios producidos a los recursos naturales no podían medirse con referencia a una disminución del valor de mercado pues tenían y tienen un valor independiente del valor de mercado, lo que la doctrina ha venido a llamar un valor intrínseco. Es por ello, que en desarrollo de las leyes anteriormente

\footnotetext{
${ }^{64}$ Consecuencia de ello ha sido la aparición de una cantidad enorme de publicaciones al respecto, entre las que destacan las siguientes series: Restoration Update, revista oficial que la Exxon Valdez Restoration Office publica, vid. http://www.oilspill.state.ak.us/ publications/publish.htm; la Restoration Notebook Series, así como sus numerosos Informes finales y anuales sobre valoración de los daños a los recursos naturales.
} 
mencionadas, en los Estados Unidos se aprobaron Reglamentos Federales que diseñaron unos procedimientos de valoración de los daños. Esos Reglamentos se aprobaron en 1986 y en 1987 y especificaban procedimientos estándares para valoraciones simplificadas que requirieran un mínimo de observación de campo, eran los denominados procedimientos del Tipo A y procedimientos alternativos que determinaran la clase y el alcance de los perjuicios a corto y largo plazo, la destrucción o pérdida de recursos en casos concretos, eran los denominados procedimientos del Tipo B. El Trustee Council en el diseño de su Plan de actuación consideró que los procedimientos del Tipo A no eran aplicables al caso del Exxon Valdez, y aunque afirmó que los del Tipo B sí, no concretó si los iba a aplicar o no. Aún así, el problema principal que planteaban los Reglamentos en su aplicación consistía en que los procedimientos de valoración de daños del Tipo B, restringían el cálculo de los daños de los recursos naturales al menor entre, por un lado, los costes de restauración o la sustitución y por otro, la disminución del valor de uso.

Completando lo anterior, es necesario resaltar que esta restricción de la valoración de los daños fue considerada por los Tribunales Estadounidenses ilegal y, por tanto, contrarios a la Comprehensive Environmental Response, Compensation, and Liability Act, un año antes de que acaeciera el accidente del Exxon Valdez en el asunto State of Ohio v. United States Department of the Interior ${ }^{65}$. La sentencia de este asunto además se pronunció aclarando que las cuantías recuperadas por daños que excedieran los costes de la restauración o sustitución debían gastarse en adquirir el equivalente de los recursos perdidos, aun cuando el recurso original hubiera podido ser restaurado de hecho. Además, la Corte afirmó claramente que la jerarquía de métodos de valoración de los daños establecida en el Reglamento Federal no era válida, por no ser un desarrollo adecuado de la Comprehensive Environmental Response, Compensation, and Liability Act, pues en vez de crear un amplio abanico de métodos de valoración de los daños, el Reglamento primaba al valor de mercado como método de valoración principal, sin que se pudieran utilizar otros métodos para calcular los daños a menos que el recurso en cuestión no estuviera comprendido en un mercado razonablemente competitivo y el valor de mercado no pudiera concretarse, sin embrago el sentido de la Comprehensive Environmental Response, Compensation, and Liability Act, según la Corte, reposaba en que al valorarse los daños producidos, y con igual importancia, se tuvieran en cuenta todos los valores, no sólo ni

\footnotetext{
65 Vid. State of Ohio v. United States Department of the Interior, 880 F.2d 432 (D.C. Cir.), reh'h denied, 897 F.2d 1151 (D.C. Cir. 1989).
} 
principalmente el valor de uso medido a través del valor de mercado, sino también todos los valores intrínsecos y no de mercado de los recursos. Entre este último tipo de valores, la Corte recurrió en el asunto State of Ohio v. United States Department of the Interior, como ejemplos, a los valores de opción y de existencia, ya analizados en otros epígrafes de este estudio.

Con este contexto jurídico, hay que valorar positivamente que los distintos Planes de restauraciones realizados por el Trustee Council, mostraran una evolución en cuanto a los procedimientos seguidos en la valoración de los daños causados por la descarga de hidrocarburos del superpetrolero Exxon Valdez, ya que en su Plan de 1989, de los nueve estudios económicos, ocho pretendían medir la disminución del valor de mercado de los recursos naturales afectados por la descarga, mientras que uno pretendía determinar la pérdida de valor intrínseco de los recursos naturales debido al accidente del buque Exxon Valdez, determinando los valores de opción, de existencia, de cuasi-opción y de legado de los recursos naturales dañados. Tan sólo un año después, en el plan de 1990, el Trustee Council reconoció claramente que, al valorar los daños causados a los recursos naturales, los daños no debían limitarse a la disminución de su valor de mercado y reformulando los diversos estudios económicos que debían seguir realizándose, consideró que no sólo debía de ser tenido en cuenta la disminución del valor de mercado, sino también las alteraciones que habían sufrido los valores intrínsecos de los recursos naturales dañados por la descarga de hidrocarburos.

\section{Hitos a destacar}

Importantes consecuencias jurídicas ha tenido el accidente del superpetrolero Exxon Valdez así como todas las actuaciones posteriores que intentaron remediar sus efectos. Una de esas consecuencias, y que es sobre la que hemos pretendido incidir, es la evolución de los procedimientos y técnicas de valoración de los daños ambientales, la evolución del valor de mercado a los valores intrínsecos de los recursos naturales que obligaron, una vez puesta de manifiesto las lagunas normativas, nacionales e internacionales, a la reforma de normas de Derecho interno en Estados Unidos. En esta evolución jugó un papel fundamental la jurisprudencia que declaró ilegal el Reglamento de 1989 de desarrollo de la Comprehensive Environmental Response, Compensation, and Liability Act y que aplicó un criterio interpretativo amplio de la mencionada Ley en la determinación de los daños ambientales aplicando criterios como el valor de opción y el valor de existencia hasta el momento no tenidos en cuenta y que hicieron que en el asunto Exxon Valdez se llegaran a conjugar valores como el de opción, de existencia, de cuasi-opción y de legado de los recursos naturales dañados. 


\section{CONCLUSIONES}

Con este trabajo hemos intentado reflejar los problemas que se plantean en la valoración del daño ambiental y a los que nuestro sistema jurídico de responsabilidad medioambiental no puede responder por adolecer de la regulación necesaria que establezca los criterios valorativos a seguir. Es cierto que se trata de una necesidad legislativa que presenta una dificultad añadida, pues la fijación de los criterios para la valoración del daño ambiental no es una cuestión exclusivamente jurídica, sino que necesita de una delimitación técnicoeconómica previa.

En cualquier caso, parece claro que sin la valoración del daño ambiental no puede articularse, con unas mínimas garantías de éxito, un sistema de resarcimiento de daños al medio ambiente. Sin saber lo que cuesta reparar un daño no se puede exigir la reparación o indemnización del mismo. Es cierto que hoy en día existen mecanismos para la determinación de los perjuicios ambientales, pero, entendemos que se adolece de estructuras ordenadas, consensuadas y normativizadas que permitan obtener un sistema de valoración del daño ambiental con todas las garantías.

Además, los criterios de determinación del daño ambiental y los métodos utilizados en la práctica para la valoración del daño ambiental expuestos en este trabajo proporcionan unas respuestas a la valoración del daño parciales e inconclusas, pues no responden a un contexto jurídico, fundamental a la hora de plantear una visión integral de un sistema de valoración del daño ambiental, y que además deja muchas cuestiones sin resolver como por ejemplo:

¿Cuándo se debe valorar el daño ambiental? El momento exacto o dies a quo de valoración del daño ambiental, ¿debe ser el momento preciso en el que ocurre el citado daño?, o cuándo se manifiestan sus efectos, o se elimina la situación ilícita, o bien, cuándo el Juez o Tribunal fija la cuantía a indemnizar o con la que hay que reparar. Podríamos acudir para responder a la pregunta a la teoría de la prescripción a efectos de determinar el momento de comisión del daño ambiental. Pero esta teoría que puede ser enormemente útil para daños no ambientales, cuando hablamos de éstos hay que tener en cuenta determinados factores o situaciones reales que no acontecen en los daños que podríamos denominar "tradicionales" y que sí están presentes en el daño ambiental. Por poner sólo algunos ejemplos, la separación existente entre la industria contaminante y el daño ambiental ocasionado a un bosque situado a kilómetros de distancia; la multiplicidad de fuentes contaminantes; la posibilidad de que el daño ambiental no se manifieste en el momento de la contaminación sino hasta 
pasado un tiempo; las distintas explicaciones científicas que puede tener un mismo hecho dañoso al medio ambiente, etc.

Pero no sólo existen problemas en cuanto a la determinación del dies a quo, pues si tenemos en cuenta los efectos extendidos en el tiempo que tienen los daños ambientales, resulta que también existen serios problemas para determinar el momento final o dies a quem de valoración de un determinado daño ambiental. No obstante, parece claro que el momento final que debemos tener en cuenta para fijar el daño ambiental es el momento en el que éste ha dejado de propagar sus efectos. Entonces, ¿a qué momento nos debemos referir para cuantificar el daño ambiental causado?, ¿cuándo debemos entender que el daño ambiental ya no ocasionará más resultados adversos? Estamos, sin duda, ante cuestiones de difícil y compleja solución.

Otra cuestión no resuelta es el eventual límite de cuantificación de un daño ambiental, sobre todo cuando hablamos de daños catastróficos. Hay muchas situaciones que pueden concebirse en las que quizás no sea posible ni la restauración ni el restablecimiento del medio ambiente a su estado original. Los casos de especies endémicas o de ecosistemas exclusivos o únicos son buenos ejemplos. Lo que nos lleva a otro tema, ¿Cómo se cuantifica la desaparición de una especie? Evidentemente a eso no se le puede poner precio, ¿̇o sí?

Además, existen otras situaciones donde, aún siendo el daño ambiental muy costoso, si es posible la reparación, pero la reparación in natura o indemnización es de tal magnitud que pueden hacer quebrar a las empresas que ocasionan los daños, por muy grandes y solventes que éstas sean. Si a ello se añade que la situación de que los seguros contratados, si es que se contratan, no cubren la totalidad de la reparación y los fondos de garantía, si es que existen, no llegan a pagar la cantidad económica que hay que abonar, podemos concluir que en muchas ocasiones es la propia Administración pública la que debe asumir la reposición de los bienes ambientales y hacer frente a las indemnizaciones, sin perjuicio de que luego pueda ejercer acciones de repetición contra el causante del daño.

En definitiva, la falta de un sistema de valoración del daño ambiental deviene en un problema de seguridad jurídica para el responsable del daño ambiental que tiene que hacer frente económicamente al mismo. Por ello, es necesario, con todas las dificultades que ello conlleva, afrontar la valoración del daño ambiental por el legislador español, de forma que se establezca el sistema o método de valoración ambiental que permita cerrar el sistema de responsabilidad medioambiental y hacer efectivo el resarcimiento de los daños al medio ambiente. 


\section{BIBLIOGRAFÍA}

API Publication $\mathrm{n}^{\circ}$. 4308. American Petroleum Institute, Washington, DC, USA; SPOONER, M.F. (editor) (1978).

ARRIBAS HERGUEDAS, F., "Del valor intrínseco de la naturaleza", Revista Isegoría. Consejo Superior de Investigaciones Científicas, Núm. 34, 2006.

AZQUETA, D. y PÉREZ, L., El valor económico de los servicios recreativos de los espacios naturales, McGraw -Hill, Madrid, 1997.

AZQUETA, D., Introducción a la Economía Ambiental, McGraw-Hill, Madrid, 2002.

BADENES CASINO, M. M. "IXtoc-1" en La práctica internacional en materia de responsabilidad por accidentes industriales catastróficos / coord. por JUSTE RUIZ, J. y SCOVAZZI, T. 2005.

BARRANTES MORENO, G., "Evaluación Económica-ecológica, la doble dimensión del daño ambiental", en Revista Gerente Número VI, San José, 2000.

BELLIER, P. and MASSART, G. (1979). The Amoco Cádiz oil spill cleanup operations-an overview of the organisation, control and evaluation of the cleanup techniques employed. Proceedings of the 1979 Oil Spill Conference.

BLANCO LOZANO, C., "Víctima y Reparación en el Delito Ambiental", $R e^{-}$ vista de Derecho Ambiental, ${ }^{\circ}$ 18, 1997.

BOU FRANCH, V. Capítulo VIII: Exxon Valdez en La práctica internacional en materia de responsabilidad por accidentes industriales catastróficos, Coord. SGOVAZZI, T. y JUSTE RUIZ, J. Tirant lo Blanc, Valencia, 2005.

BOWMAN M. \& BOYLE A., Environmental Damage in International \& Comparative Law: Problems of Definition and Valuation, Oxford University Press; 2002.

CAFFERATTA, N., "Daño ambiental colectivo y proceso civil colectivo" Ley 25675, Revista de Responsabilidad civil y Seguros, Año V, No II, marzo-abril 2003.

CAFFERATTA, N., "Prueba y nexo de causalidad en el Daño Ambiental", en obra colectiva Meio Ambiente e Acceso à Justiça. Homenagem a Vladimir PASSOS DE FREITAS, Volumen 3, $11^{\circ}$ Congreso Internacional de Direito Ambiental, 27 de Maio a $1^{\circ}$ de Junho de 2007, Sao Paulo, Brasil, Instituto O Direito po um Planeta Verde, Imprenta Oficial do estado de Sao Paulo.

CAFFERATTA, N., "Daño ambiental/Jurisprudencia", Revista Furídica La Ley, Año LXIII, número 131, Buenos Aires, 2003.

CASIMIRO HERRUZO, A., "Fundamentos y métodos para la valoración de bienes ambientales", Jornada Temática: Aspectos Medio Ambientales de la Agricultura, Libro Blanco de la Agricultura y el Desarrollo Rural, Madrid, 2002. 
CASTAÑÓN DEL VALLE, M., Valoración del daño ambiental, Programa de las Naciones Unidas para el Medio Ambiente (PNUMA), 2006

CONAN, G., D'OZOUVILlE, L., and MARCHAND, M. (1978). Amoco Cádiz-preliminary observations of the oil spill impact on the marine environment. One day session, Amoco Cádiz, Brest, France, 7 June 1978. Le Centre National pour l'Exploitation des Oceans, París, France.

DE ALBA, E. y REYES, M. E., "Valoración económica de los recursos biológicos del país", en la obra La Diversidad Biológica de México: Estudio de País 1998, Conabio, Comisión Nacional para el Conocimiento y Uso de la Biodiversidad, México, 1998.

DÍAZ, L.M. "Responsabilidad del Estado y contaminación. Aspectos jurídicos", México, Porrua, 1982.

GÓMEZ ROBLEDO VERDUZCO, "A Propósito del Ixtoc-1", Anuario Jurídico, 1983, pp. 411 y ss.; ibíd., Temas selectos de Derecho Internacional, 1." ed., México, UNAM, Instituto de Investigaciones Jurídicas, 1986.

GONZÁLEZ, R., "Recomendaciones para la caracterización del daño ambiental" en Temas de Derecho Ambiental, Editorial Investigaciones Jurídicas S.A., 2001, Costa Rica.

GUERRERO ZAPLANA, J., La responsabilidad medioambiental en España, Ed. La Ley, Madrid, 2010.

JERNELÓV y LINDEN, "Ixtoc-1: A Case Study of the World's Largest Oil Spill”.

JOHANSSON, P.O., Cost-Benefit analisys of environmental change, Cambridge University Press, Cambridge, 1993.

KISS, "L'affaire de l'Amoco Cádiz: responsabilité pour une catastrophe écologique", en Journal de Droit International, 1985.

KRISTÖM, B y RIERA, P. "El método de valoración contingente. Aplicaciones al medio rural español", Revista Española de Economía Agraria, n ${ }^{\circ}$ 179, págs. 133-165, 1997.

LEAL, J., "Técnicas de Valorización Económica de Impactos Ambientales: Aplicabilidad en el caso del sector minero", Revista del CIPMA, Chile, Marzo 2000.

LINARES LLAMAS, P. y ROMERO PÉREZ, C., "Economía y Medio Ambiente: herramientas de valoración ambiental", en la obra coordinada por BECKER ZUAZUA, F., CAZORLA PRIETO L.M, y MARTÍNEZSIMANCAS SÁNCHEZ, J., Tratado de Tributación Medioambiental, Aranzadi, Cizur Menor. 2008.

LÓPEZ, D. A. "Antecedentes y comentarios del accidente del pozo Ixtoc-1 y de los juicios derivados del mismo en los Estados Unidos de América en contra de Petróleos Mexicanos", Pemex Lex, enero-febrero 1991.

LOZANO CUTANDA, B., "La responsabilidad por daños ambientales: la si- 
tuación actual y el nuevo sistema de "responsabilidad de derecho público" que introduce la directiva 2004/35/CE", Medio Ambiente y Derecho, Revista Electrónica de Derecho Ambiental, nº12-13, 2005.

LOZANO CUTANDA, B., Comentario Ley Responsabilidad Medioambiental, Ed. Civitas, Madrid, 2008.

LOZANO CUTANDA, B., Derecho Ambiental Administrativo, Ed. La Ley-Actualidad, 2010, $11^{\text {a }}$ Edición.

LUCGHINI, "Le procès de l'Amoco Cádiz: présent el voies de futur", en Annuaire français de Droit International, 1985.

Manual de Valoración de la Biodiversidad. Handbook of Biodiversity Valuation. A Guide for Policy Makers, OECD, 2002.

MERIALDI, A. "Patmos y Havem en La práctica internacional en materia de responsabilidad por accidentes industriales catastróficos, Coord. SCOVAZZI, T. y JUSTE RUIZ, J. Tirant lo Blanc, Valencia, 2005.

ORTEGA ÁlVAREZ, L. (Dir.), Lecciones de Derecho del Medio Ambiente, Lex Nova, Valladolid, $4^{\text {a }}$ edición, 2006.

PAVALEK ZAMORA, E., "Valoración Económica del Medio Ambiente desde la Perspectiva Aseguradora: La Economía frente al Derecho", Revista Trébol, no 30, enero 2004.

PEARGE, D.W y TURNER, K.H., Economía de los recursos naturales y del medio ambiente, Celeste, Madrid, 1995.

PEÑA CHACÓN, M, "La Legitimación Procesal en el Derecho Ambiental", Revista Furídica Lex Difusión y Análisis, año VII, Nº 93, marzo 2003, Editora Laguna, México, y en Revista de Direito Ambiental, año 8, enero-marzo 2003, número 29, Editorial Dos Tribunais, Brasil.

PEÑA CHACÓN, M., "Reparación y valoración económica de los daños causados al medio ambiente", Medio Ambiente y Derecho, Revista Electrónica de Derecho Ambiental, n' 12-13, 2005.

PEÑA CHACÓN, M., "La nueva directiva comunitaria sobre responsabilidad ambiental en relación con la prevención y reparación de los daños ambientales y su relación con los regímenes latinoamericanos de responsabilidad ambiental", Revista Lex Difusión y Análisis, año IX, febrero 2005, número 116, México.

PEÑA CHACÓN, M., "Daño Ambiental y prescripción", Medio Ambiente y Derecho, Revista Electrónica de Derecho Ambiental, no 19, 2009.

PÉREZ PINTOS, M. y VÁZQUEZ REINOSO, E., "Valoraciones Económicas de Daños en el Medio Ambiente", Revista Guardabosques (www.guardabosques.net), febrero 2002.

PRADA, A., GONZÁLEZ M., POLOMÉ, P., GONZÁLEZ X.M. y VÁZQUEZ, M.X., Valoración económica del patrimonio natural, Instituto de Estudios Económicos, Fundación Pedro Barrié de la Maza, A Coruña. 
RIERA, P, Manual de Valoración Contingente, Instituto de Estudios Fiscales, Madrid, 1994.

ROMERO, G., Economía de los recursos ambientales y naturales, Alianza Economía, Madrid, 1997.

ROSEN, S., "Hedonic prices and implicit markets: Product diferentiation in pure competition", Fournal of Political Economy, 82 (1), pp. 21-38, 1974.

RUDA GONZÁLEZ, A., El daño ecológico puro: la responsabilidad civil por el deterioro del medio ambiente, con especial atención a la Ley 26/2007, de 23 de octubre, de responsabilidad medioambiental, Thomson-Aranzadi, 2008.

SÁNCHEZ SÁEZ, A.J., "La "restitutio in pristinum" como mecanismo deseable para la reparación de los daños causados al medio ambiente", Medio Ambiente y Derecho, Revista Electrónica de Derecho Ambiental, nº 3, 1999.

SCOVAZZI, T. "Amoco Cádiz" ; SCOVAZZI, T. "La sentenza sul risarcimento dei danni nel caso Amoco Cádiz”, en Rivista Giuridica dell'ambiente, 1988. The Amoco Cádiz oil spill. Special edition of Marine Pollution Bulletin 9 (7). Pergamon Press, Oxford and New York.

SERRANO MORENO, J.L., Ecología y Derecho, Granada, 1992.

VÁZQUEZ BOTELLO y VILLANUEVA, Study of the Penaeid Shrimp population in relation to petroleum hydrocarbons in Campeche Bank, $R e^{-}$ view of the Health of the Oceans. Mexican Region of the Gulf of Mexico, México, Centro de Ciencias del Mar y Limnología, UNAM, México, 1987.

VÁZQUEZ BOTELLO, A. "Golfo de México: contaminación e impacto ambiental: diagnóstico y tendencias", Edición. Univ. A. de Campeche, UNAM, Instituto Nacional de Ecología, 2005.

VÁZQUEZ GARCÍA, A., "La Responsabilidad por Daños al Ambiente", $M e^{-}$ morias del Segundo Encuentro Internacional de Derecho Ambiental, México, 2004. 